Research Article

\title{
Temperature Gradient and Its Effect on Long-Span Prestressed Concrete Box Girder Bridge
}

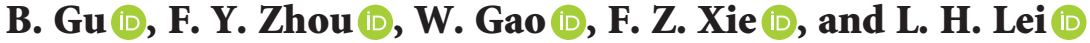 \\ Faculty of Civil Engineering and Mechanics, Jiangsu University, Zhenjiang 212013, China \\ Correspondence should be addressed to B. Gu; gubin@ujs.edu.cn
}

Received 21 January 2020; Revised 8 July 2020; Accepted 3 August 2020; Published 31 August 2020

Academic Editor: Melina Bosco

Copyright $\odot 2020$ B. Gu et al. This is an open access article distributed under the Creative Commons Attribution License, which permits unrestricted use, distribution, and reproduction in any medium, provided the original work is properly cited.

\begin{abstract}
Temperature variations in the girder at two cross-sections of a long-span prestressed concrete box girder bridge (PCBG) were analysed based on measured data. The results show that the temperature distribution in the concrete box girder (CBG) is strongly influenced by its size, and the temperature distribution in the girder changes along the longitudinal direction of the bridge. To clarify the temperature distribution in the long-span PCBG bridge, a two-dimensional (2D) temperature prediction model, validated by the measured data, was proposed, and the effect of the girder size on the temperature distribution of the CBG was studied using the model. Based on the results of the studies, simplified vertical and transverse temperature gradient models that could consider changes along the longitudinal direction of the bridge were proposed and validated by using the measured data and three-dimensional (3D) mechanical finite element model (FEM) of the bridge. Then, the deformations and stresses derived from the proposed temperature gradient models and the models according to different codes were studied and compared. Finally, conclusions and recommendations for future bridge design are provided.
\end{abstract}

\section{Introduction}

Long-span PCBG bridges are generally built in open areas, and they are inevitably influenced by environmental thermal loads. Owing to the poor thermal conductivity of concrete, environmental thermal loads will create nonuniform temperature distributions in bridge structures. The stresses and deformations caused by nonuniform temperature distributions can be comparable to those caused by dead and live loads and may cause cracks and excessive deformations $[1,2]$. Therefore, it is crucial for designers to consider temperature effects when designing a bridge.

For design purposes, solar temperatures in bridge structures must be known; therefore, a large number of studies have been performed in the last half century. Priestley [3] proposed a fifth-order vertical temperature gradient model by analysing the temperature distributions of concrete bridges. Roberts-Wollman et al. [4] compared the maximum measured positive and negative temperature gradients of a box girder bridge to the fifth-order curve and concluded that the positive and negative temperature gradient curves could all be approximated with a fifth-order parabola. To determine the temperature gradient in prestressed concrete girders, Lee [5] studied the temperature distributions in a prestressed BT-63 concrete girder segment and developed vertical and transverse temperature gradients. Tayşi and Abid [6] and Abid et al. [7] analysed the temperature distributions in a CBG by using experimental methods and finite element (FE) simulation methods. Kim et al. [8] and Zhou et al. [9] investigated the temperature variations in a steel box girder based on monitoring data and numerical simulations. Abid et al. [10] studied the temperature gradient distributions in concrete-encased structures based on experimental data and a thermal FE parametric study. Recently, with the development of structural health monitoring technology, structural health monitoring systems have been installed on an increasing number of bridges. Therefore, many researchers have studied the temperature gradient and its effect on bridges by using monitoring data. Lucas et al. [11] analysed the extreme temperatures of a box girder based on measured data. Lei et al. [12] calculated the extreme values of the vertical 
differential temperature of a CBG based on the measured temperature. Song et al. [13] proposed temperature gradient models for CBGs by analysing measured temperature data. Yang et al. [14] investigated the temperature field and displacement of a steel box girder and tower of a highway cable-stayed bridge based on measured data.

However, only a limited number of studies regarding the temperature gradients and their effect on long-span PCBG bridges have been conducted. Li et al. [15] compared the stresses calculated from the Priestley model and the observed temperature data and found that the stresses calculated by the Priestley model for deep sections of the Confederation Bridge disagree with the observations in the bottom slab. Hedegaard et al. [16] measured temperature gradients through a section of a CBG bridge over the course of 3 years. The stresses and deformations of the bridge for the largest measured temperature gradients were compared with the results predicted by FE modelling given the applied design gradients. Wang and Ye [17] and Song et al. [18] studied the thermal behaviours of long-span PCBG bridges during cantilever construction. However, unlike other types of bridges, the girder size of a long-span PCBG bridge changes along the longitudinal direction of the bridge. The size of the girder near the intermediate piers is considerably larger than that of the girder at the midspan. The depth, web thickness, and bottom slab thickness of the girder near the intermediate piers can reach $10 \mathrm{~m} \sim 15.7 \mathrm{~m}, 0.6 \mathrm{~m} \sim 1 \mathrm{~m}$, and $1 \mathrm{~m} \sim 1.8 \mathrm{~m}$, respectively, while those dimensions of the girder at the midspan only reach $2.5 \mathrm{~m} \sim 5 \mathrm{~m}, \quad 0.3 \mathrm{~m} \sim 0.5 \mathrm{~m}$, and $0.3 \mathrm{~m} \sim 0.4 \mathrm{~m}$, respectively [19]. The cross-sectional shape is an important factor that affects the temperature distribution in a bridge structure. The CBG near the intermediate piers is more likely to be affected by transverse temperature gradients than the CBG near the midspan, and the vertical temperature gradients in the CBG near the intermediate piers and midspan may be different $[15,20,21]$. However, the bridge temperatures along the longitudinal direction are usually recognized as constant, so it is valuable to study the temperature gradient and its effect on long-span PCBG bridges considering the changes in its cross-section.

With regards to this need, the measured temperatures in a long-span PCBG bridge were analysed. A 2D temperature predicting model and a 3D mechanical FEM, validated by the measured data, were then used to analyse the temperature gradient and its effect on long-span PCBG bridges. After the analysis, vertical and transverse temperature gradient models that could consider the changes along the longitudinal direction of the long-span PCBG bridge were proposed and validated. Then, the thermal behaviour derived from the proposed temperature gradient models and the models according to different codes were studied and compared. Finally, conclusions and recommendations for future bridge design are provided.

\section{Description of the Bridge and Its Monitoring System}

As an example, the auxiliary shipping channel bridge of the SuTong Bridge is selected to study the temperature gradient and its effect on long-span PCBG bridges. This is a long-span rigid-frame concrete bridge with a continuous span of $140+268+140=548 \mathrm{~m}$ (see Figure 1). The bridge over the Yangtze River is located at $31.7^{\circ} \mathrm{N}, 121^{\circ} \mathrm{E}$, and the azimuth of its axis is $-13^{\circ}$ (the angle is between the axis and south direction and positive in the counterclockwise direction). The superstructure is made of two separate bridges constructed parallel to a single CBG, with one carrying southbound traffic and the other carrying northbound traffic. The total deck width of the box girder is $16.4 \mathrm{~m}$, and the depth of the box girder varies from $15.0 \mathrm{~m}$ at the intermediate piers to $4.5 \mathrm{~m}$ at the midspan. The paving scheme of the bridge deck is 110 -mm-thick asphalt concrete.

The bridge has several systems for monitoring the responses of the bridge under various kinds of environmental actions. There are two cross-sections whose temperatures are monitored and four cross-sections whose strains are monitored. The sections are shown in Figure 1, and some characteristic dimensions and the layout of the sensors in the sections are shown in Figure 2. For meteorological parameters, anemometers and air temperature sensors are installed above the top surface of the girder at the centre of the main span. All dates are collected at 30-minute intervals.

\section{Temperature Measurement Data and Preliminary Analysis}

The solar radiation intensity is the main factor that affects the temperature distribution in the bridge. Critical temperature distributions usually occur in summer due to the higher solar radiation intensity received on the deck surface. Therefore, the measured data from June 1 to August 31, 2010, are selected for analysis. The hourly records of the air temperature and wind speed are shown in Figure 3. The daily maximum air temperature often occurs at approximately 14: 00 to $16: 00$, and the daily changing range of the air temperature can reach $9.3^{\circ} \mathrm{C}$. The wind speed changes irregularly with time, and the maximum and minimum wind speeds are $16.0 \mathrm{~m} / \mathrm{s}$ and $0.2 \mathrm{~m} / \mathrm{s}$, respectively, while the maximum and minimum daily average wind speeds are $1.9 \mathrm{~m} / \mathrm{s}$ and $8.7 \mathrm{~m} / \mathrm{s}$, respectively.

Figure 4 shows the measured temperatures of the girders at sections T1 and T2 from June 1 to August 31, 2010. As seen from Figures 3 and 4, the temperatures of the girders and the monitoring air temperatures all have the same changing tendency. The measured temperature and its changing rate mainly depend on the distance of the sensors to the outer surface and the solar radiation intensity received on the outer surface. The longer the distance of the sensors to the outer surface is, the lower the temperature and temperature change rate are. The higher the solar radiation intensity received on the outer surface is, the higher the temperature and temperature change rate are. For example, the temperature and its change rate for sensors T2/7 and T2/18 are all lower than those of sensors $\mathrm{T} 2 / 8$ and T2/19, respectively. In addition, although the distance from sensor T1/1 to the outer surface is longer than that of sensor T2/1, the measured temperature and its fluctuation for sensor T1/1 are all higher than that of sensor T2/1. The only probable reason for 


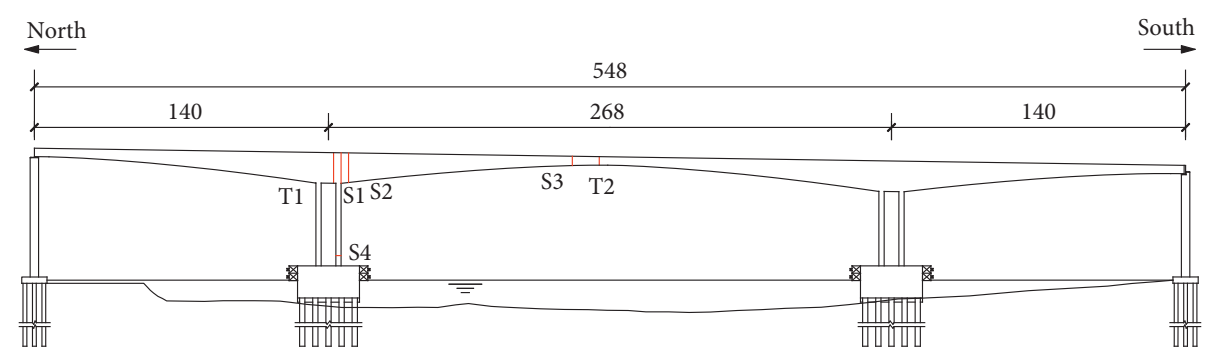

FIgURE 1: The auxiliary shipping channel bridge of the SuTong Bridge (unit: $\mathrm{m}$ ).

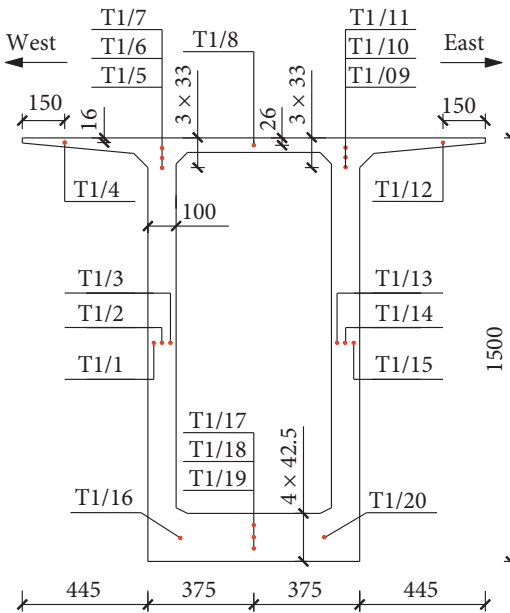

- Temperature sensor

- Vibrating wire strain sensor

(- Nonstress vibrating wire strain sensor

(a)

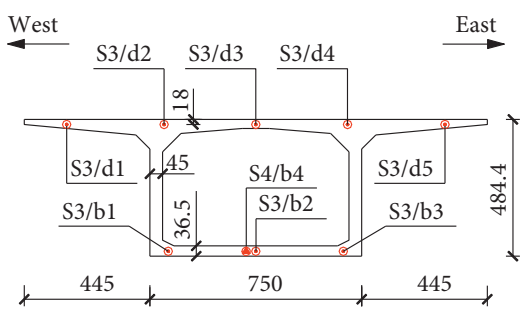

- Temperature sensor

- Vibrating wire strain sensor

(4) Nonstress vibrating wire strain sensor

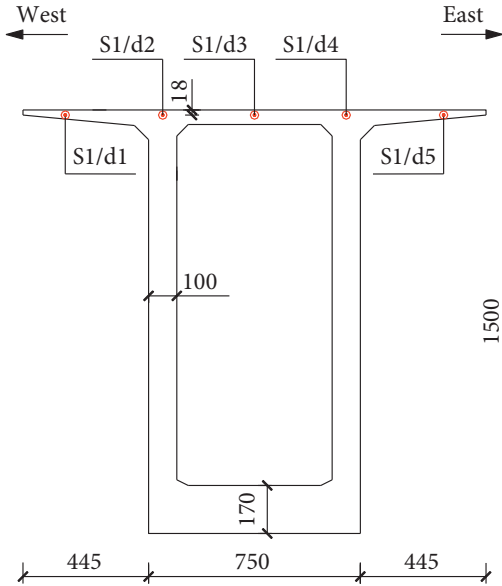

- Temperature sensor

- Vibrating wire strain sensor

- Nonstress vibrating wire strain sensor

(b)

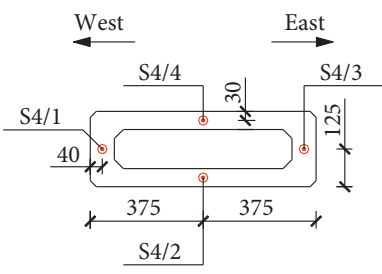

- Temperature sensor

- Vibrating wire strain sensor

- Nonstress vibrating wire strain sensor
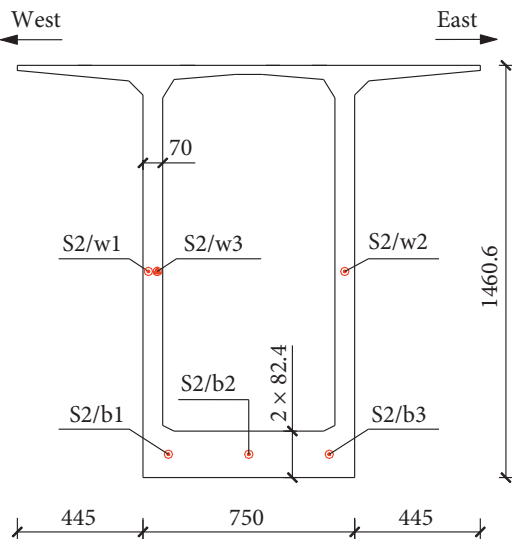

- Temperature sensor

- Vibrating wire strain sensor

(4) Nonstress vibrating wire strain sensor

(c)

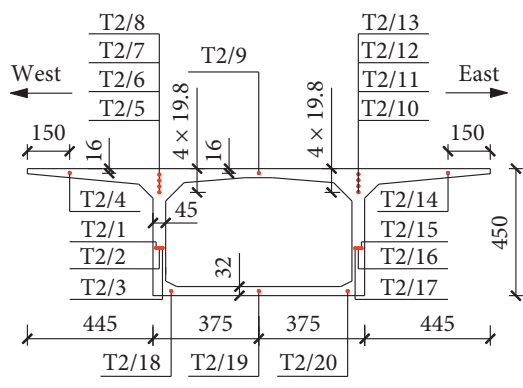

- Temperature sensor

- Vibrating wire strain sensor

- Nonstress vibrating wire strain sensor

(f)

Figure 2: Characteristic section dimensions and layout of the sensors. (a) Section T1. (b) Section S1. (c) Section S2. (d) Section S3. (e) Section S4. (f) Section T2 (unit: $\mathrm{cm}$ ).

this phenomenon is that the web of section $\mathrm{T} 1$ can receive more solar radiation than section $\mathrm{T} 2$, that is, the cantilever slab of the girders near the intermediate piers may not be long enough to protect the web from solar radiation.

Interestingly, the temperatures in the bottom slab of section $\mathrm{T} 1$ are lower than those in the web, while the temperatures in the bottom slab and web of section T2 are nearly equal (see Figure 5). Due to the large area of the bottom slab and the great distance between the centroid and bottom slab, the lower temperatures in the bottom slab may contribute to the development of the worst condition. However, as far as the author knows, there are no bridge design codes worldwide that consider the negative temperature gradient in the bottom slab. A longitudinal temperature difference exists in the web and bottom slab, as shown in Figure 6. The longitudinal temperature difference 


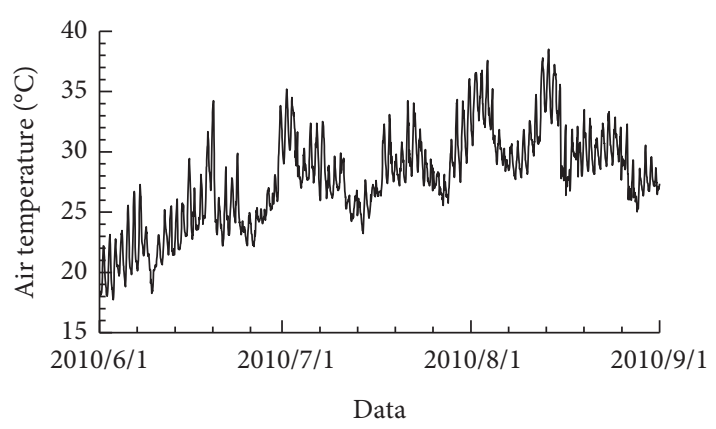

(a)

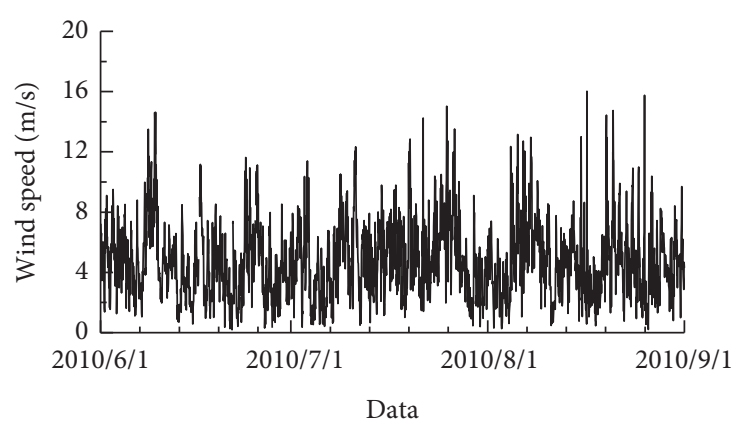

(b)

Figure 3: Hourly environmental records for the period from June 1 to August 31, 2010: (a) air temperature and (b) wind speed.

in the web (temperature difference between T2/02 and T1/ 02 ) and in the bottom slab (temperature difference between $\mathrm{T} 2 / 19$ and $\mathrm{T} 1 / 18$ ) can reach $5.4^{\circ} \mathrm{C}$ and $2.5^{\circ} \mathrm{C}$, respectively. According to Figures 3-6, it can also be found that the critical temperature gradients in sections $\mathrm{T} 1$ and $\mathrm{T} 2$ are easily reached on sunny days after a substantial several days warming trend.

Through the above analysis, we know that the temperature distribution in the CBG depends on its size; therefore, the temperature distributions in the long-span PCBG bridges are very complex. However, it is difficult to investigate the temperature gradient in the long-span PCBG bridge by using the measured data at limited points. To develop the appropriate temperature gradients in the longspan PCBG bridges for design, a temperature prediction model is needed.

\section{Prediction of the Temperature in the CBG}

4.1. Heat Transfer. Although the girder size of the long-span PCBG bridge changes along the longitudinal direction of the bridge, the change rate is very slow. Therefore, it can be assumed that the heat transfer in the longitudinal direction of the bridge can be neglected, and the temperature variation over the cross-section of the girder at any time $t$ is governed by a two-dimensional heat transfer equation:

$$
\rho c \frac{\partial T}{\partial t}=k\left(\frac{\partial^{2} T}{\partial^{2} x}+\frac{\partial^{2} T}{\partial^{2} y}\right)
$$

where $x$ and $y$ are coordinates in two directions and $k, \rho$, and $c$ are the thermal conductivity coefficient, density, and specific heat, respectively. The temperature field in the crosssection of the girder at any time $t$ can be obtained by solving equation (1) under the initial and boundary conditions. For a precise determination of the temperature field in the girder, the initial and boundary conditions should be carefully studied.

4.2. Initial Condition. The initial condition is important in numerical studies; generally, the initial temperatures in the girder are assumed to be uniform at a value equal to the average of all the measured temperatures or equal to the minimum air temperature. However, this assumption usually does not agree with practical situation. Therefore, a preanalysis, in which the boundary conditions are calculated by the measured meteorological data, can be performed to eliminate the effect of the assumed initial conditions.

4.3. Boundary Conditions. The boundary conditions associated with equation (1) can be expressed as follows [22]:

$$
k \frac{\partial T}{\partial n}+q=0
$$

where $n$ is the direction of heat flow and $q$ is the heat transferred between the girder surface and the environment per unit area. Figure 7 shows the heat transferred between the girder surface and the environment. As shown, the heat transferred between the girder surface and the environment can be expressed by

$$
q=q_{\mathrm{S}}+q_{\mathrm{A}}+q_{\mathrm{G}}+q_{\mathrm{C}}-q_{\mathrm{R}}
$$

where $q_{\mathrm{S}}, q_{\mathrm{A}}$, and $q_{\mathrm{G}}$ are the heat absorbed by the girder surface due to solar radiation, atmospheric thermal radiation, and ground thermal radiation, respectively, $q_{\mathrm{C}}$ is the heat gained from or lost to the surrounding air by convection, and $q_{\mathrm{R}}$ is the radiation emitted from the girder surface.

The heat absorbed by the girder surface due to solar radiation is obtained by [22]

$$
q_{\mathrm{S}}=\alpha\left[\frac{I_{\mathrm{B}}}{\sin \beta} \cos \theta+I_{\mathrm{D}} \sin ^{2}\left(\frac{\eta}{2}\right)\right]+\alpha \zeta_{\mathrm{e}} \cos ^{2}\left(\frac{\eta}{2}\right)\left(I_{\mathrm{B}}+I_{\mathrm{D}}\right),
$$

where $\alpha$ is the solar radiation absorptivity coefficient of the girder surface, $\zeta_{e}$ is the ground reflectance value, $\theta$ is the solar incidence angle, $\eta$ is the tilt angle between the surface and horizontal plane, $\beta$ is the solar altitude, and $I_{\mathrm{B}}$ and $I_{\mathrm{D}}$ are the direct solar radiation and diffuse solar radiation on a horizontal surface, respectively. The calculations of $I_{\mathrm{B}}$ and $I_{\mathrm{D}}$ can be found in the related literature [23].

In the calculation of the solar radiation, the shadow cast on the web by the cantilever slab should be considered. The shadow depth on the web can be calculated by [5] 

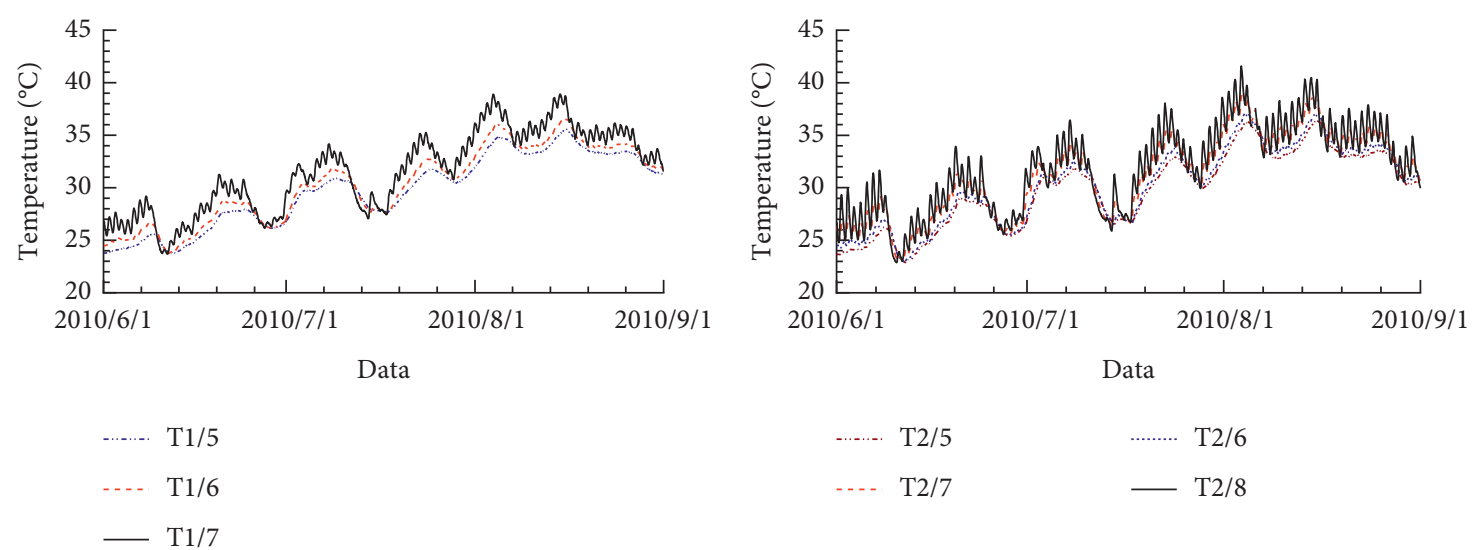

(a)

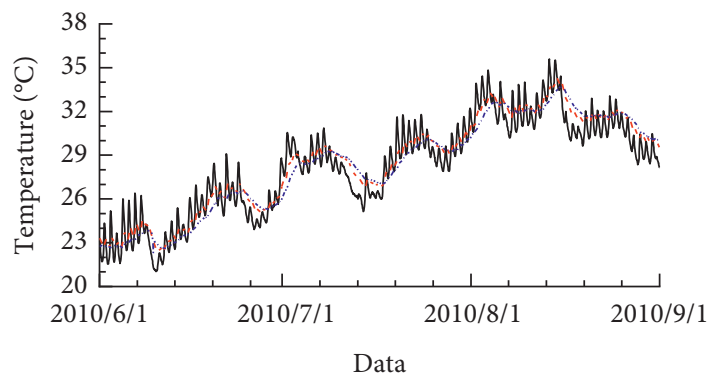

(b)

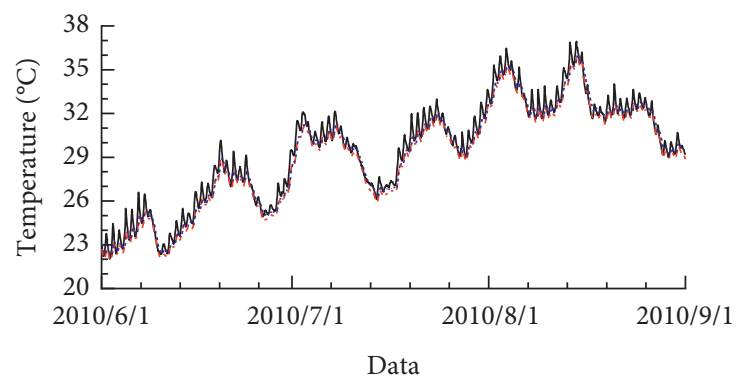

$-\mathrm{T} 1 / 1$

$-\mathrm{T} 2 / 1$

-.... $\mathrm{T} 1 / 2$

-.... $\mathrm{T} 2 / 2$

-....... $\mathrm{T} 1 / 3$

……. $\mathrm{T} 2 / 3$

(c)
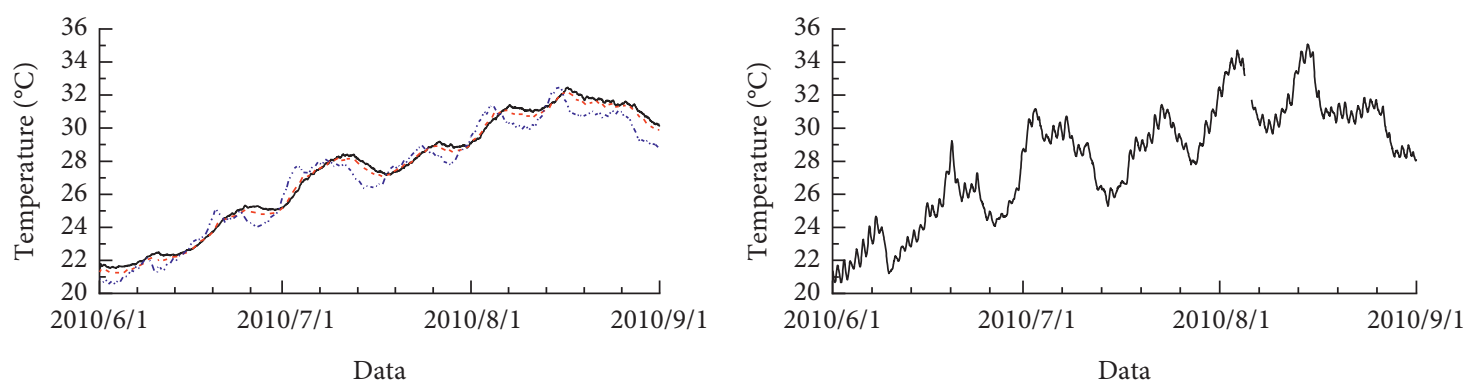

- T1/17

$\mathrm{T} 2 / 19$

-.... $\mathrm{T} 1 / 18$

-....... T1/19

(e)

(f)

Figure 4: Temperature variations of the girder at sections T1 and T2 for the period from June 1 to August 31, 2010: (a) T1/5 T1/7; (b) T2/ 5 T2/8; (c) T1/1 T1/3; (d) T2/1 T2/3; (e) T1/17 T1/19; (f) T2/19.

$$
L_{\mathrm{s}}=L_{\mathrm{c}} \frac{\tan \beta}{\cos (\varphi-\psi)},
$$

where $L_{\mathrm{s}}$ is the length of the shadow depth on the web, $L_{\mathrm{c}}$ is the length of the cantilever slab, $\varphi$ is the solar azimuth, and $\psi$ is the surface azimuth angle.

The heat absorbed by the girder surface due to atmospheric thermal radiation can be expressed as follows [10]:

$$
\begin{aligned}
q_{\mathrm{A}}= & \varepsilon_{0} \varepsilon_{\mathrm{a}} C_{0}\left(T_{\mathrm{a}}+273\right)^{4} \sin ^{2}\left(\frac{\eta}{2}\right) \\
& +\varepsilon_{0} \varepsilon_{\mathrm{a}}\left(1-\varepsilon_{\mathrm{e}}\right) C_{0}\left(T_{\mathrm{a}}+273\right)^{4} \cos ^{2}\left(\frac{\eta}{2}\right),
\end{aligned}
$$

where $\varepsilon_{0}, \varepsilon_{\mathrm{a}}$, and $\varepsilon_{\mathrm{e}}$ are the emissivity of the girder surface, ambient air, and ground, respectively, $C_{0}$ is the Stefan Boltzmann constant, and $T_{\mathrm{a}}$ is the air temperature. 


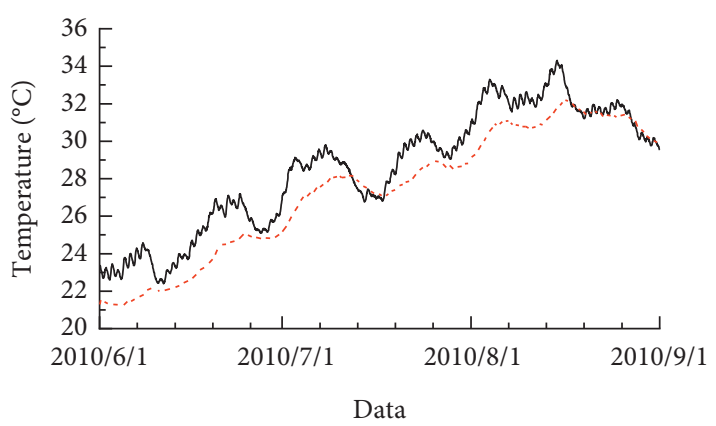

$-\mathrm{T} 1 / 2$

-.... T1/18

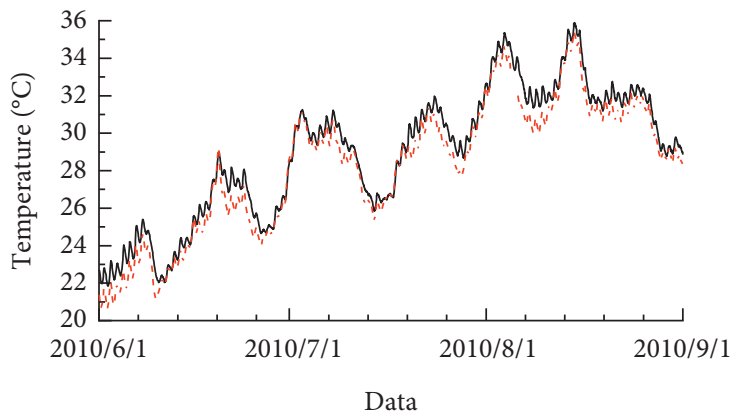

$-\mathrm{T} 2 / 2$

-.... T2/19

(a)

(b)

Figure 5: Comparison of the temperature in the web and bottom slab for the period from June 1 to August 31, 2010: (a) T1/2 T1/18; (b) T2/ 2 T2/19.

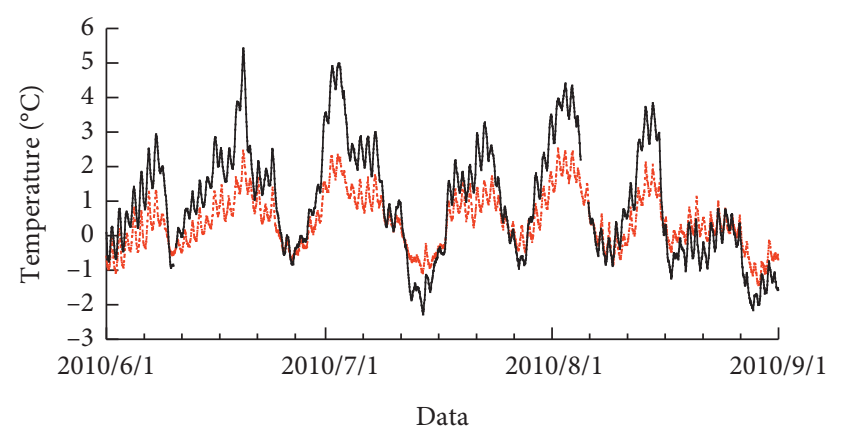

….... $\mathrm{T} 2 / 2-\mathrm{T} 1 / 2$

- T2/19-T1/18

Figure 6: Longitudinal temperature difference in the web and bottom slab for the period from June 1 to August 31, 2010.

The heat absorbed by the girder surface due to the ground thermal radiation can be expressed by [10]

$$
q_{\mathrm{G}}=\varepsilon_{0} \varepsilon_{\mathrm{e}} C_{0}\left(T_{\mathrm{e}}+273\right)^{4} \cos ^{2}\left(\frac{\eta}{2}\right)
$$

where $T_{\mathrm{e}}$ is the temperature of the ground.

The heat gained from or lost to the surrounding air by convection is depicted as follows:

$$
q_{\mathrm{Ca}}=h_{\mathrm{c}}\left(T_{\mathrm{c}}-T_{\mathrm{a}}\right),
$$

where $T_{\mathrm{c}}$ is the girder's surface temperature and $h_{\mathrm{c}}$ is the heat convection coefficient and can be calculated using the following equation [24]:

$$
h_{\mathrm{c}}= \begin{cases}4 v+5.6, & v \leq 5 \mathrm{~m} / \mathrm{s}, \\ 7.15 v^{0.78}, & v>5 \mathrm{~m} / \mathrm{s},\end{cases}
$$

in which $v$ is the wind speed.
The radiation emitted from the girder surface can be calculated using

$$
q_{\mathrm{R}}=\varepsilon_{0} C_{0} T_{\mathrm{c}}^{4}
$$

The air inside the box can also affect the temperature field in the CBG. If there is no measured temperature of the inside air, the temperature can be calculated from the average temperature of the inner surfaces by using the iterative method. The average core temperature for a fluid in an enclosed space is approximately equal to the average temperature of the inside surfaces [25]. The start value for the inside air temperature can be set to the uniform temperature of the girder, and the simulation is then repeated with a new air temperature calculated from the previous results [26].

4.4. Validation of the Proposed Model by the Measured Data. The FEMs of the CBG at sections T1 and T2, which consist of 3,680 and 2,776 elements, respectively, were built by using ANSYS (see Figure 8). The PLANE55 element, which is applicable to a $2 \mathrm{D}$ transient thermal analysis, was used for several materials including the concrete for the girder section and asphalt concrete for the pavement.

Field measurements taken from July 30 to August 3, 2010, were used to validate the FEM. The analyses were all performed hourly for five days. The initial temperature was assumed to be equal to the average of all the measured temperatures, and the preanalysis for the first four days was performed to eliminate the effect of the initial temperature. Figure 9 shows the hourly records of the air temperature, wind speed, and solar radiation density from July 30 to August 3, 2010. The solar radiation was calculated by the empirical formulas [23], and the value of the Linke turbidity factor was set to 4 . The material properties are listed in Table 1. Based on the meteorological data, the thermal boundary conditions were calculated by using equations (3)-(10) and were all applied to the FEM for transient heat transfer analysis. 


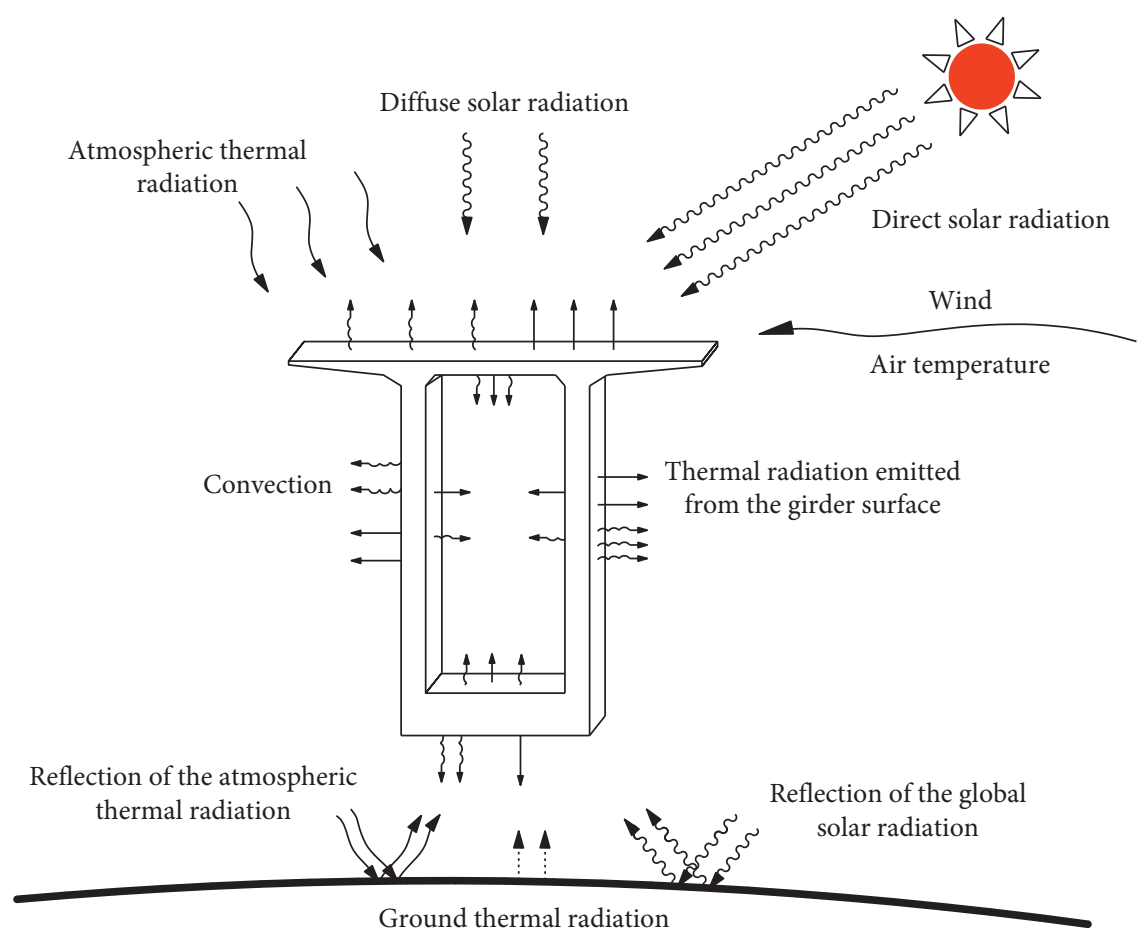

FIGURE 7: The heat transferred between the girder surface and environment.

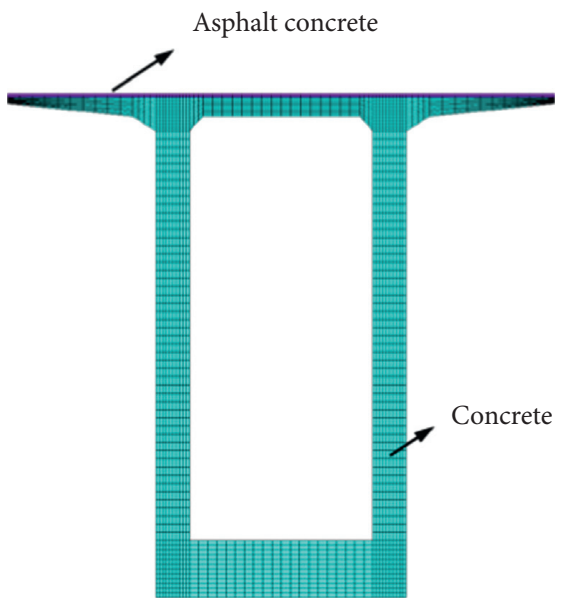

(a)

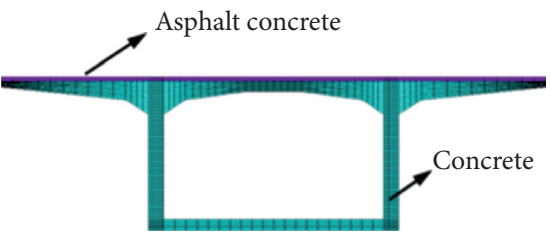

(b)

Figure 8: The FEMs of the CBG: (a) section T1 and (b) section T2.

The temperature variation in the $\mathrm{CBG}$ at sections $\mathrm{T} 1$ and T2 on August 3, 2010, was predicted and compared with the measured temperatures. Figure 10 shows the comparison between the predicted and measured temperatures for temperature sensors $\mathrm{T} 1 / 4, \mathrm{~T} 1 / 1, \mathrm{~T} 1 / 7, \mathrm{~T} 1 / 19, \mathrm{~T} 2 / 4, \mathrm{~T} 2 / 1, \mathrm{~T} 2 / 8$, and $\mathrm{T} 2 / 19$. As shown, the predicted and measured temperatures closely matched at most points. The maximum prediction error was lower than $1.5^{\circ} \mathrm{C}$, which was considered acceptable. The errors were most likely attributed to the difference between the boundary conditions of the model and the actual environment. Therefore, the model can accurately predict the temperature variation of a CBG and can be used to study the temperature distributions in a long-span PCBG bridge.

\section{Investigation of the Temperature Distribution in the CBG}

To study the temperature distributions in the CBG, four sunny days, when the temperature differences between T2/8 and T2/2 were relatively large, were selected for analysis. The weather conditions of the four sunny days are presented in Table 2. For each day, the vertical temperature distributions 


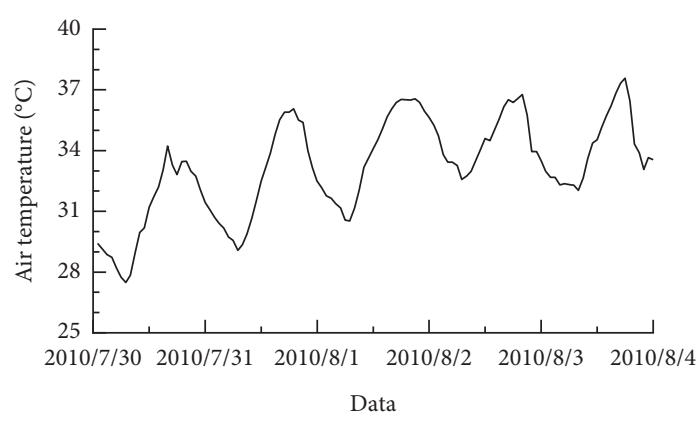

(a)

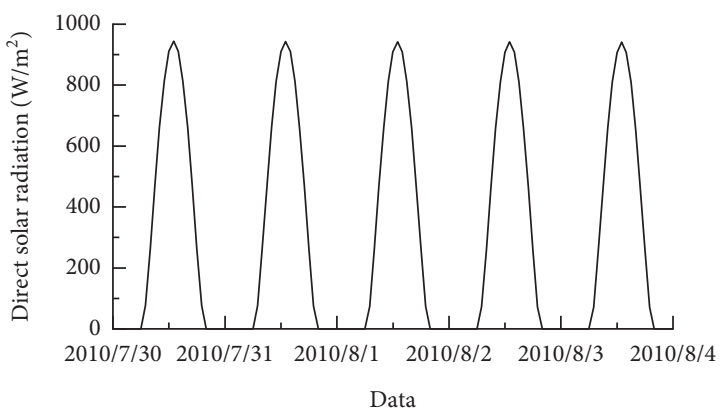

(c)

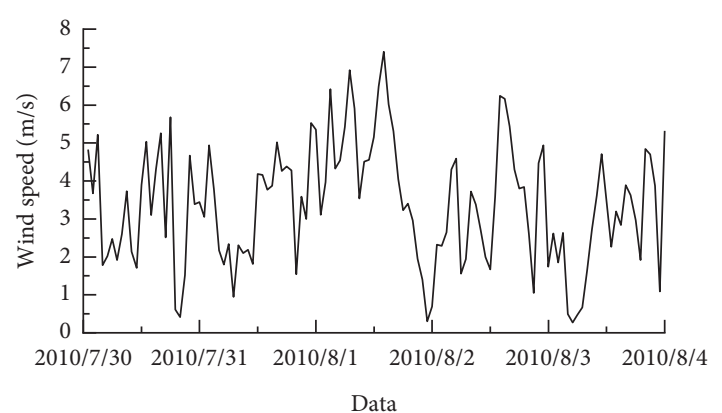

(b)

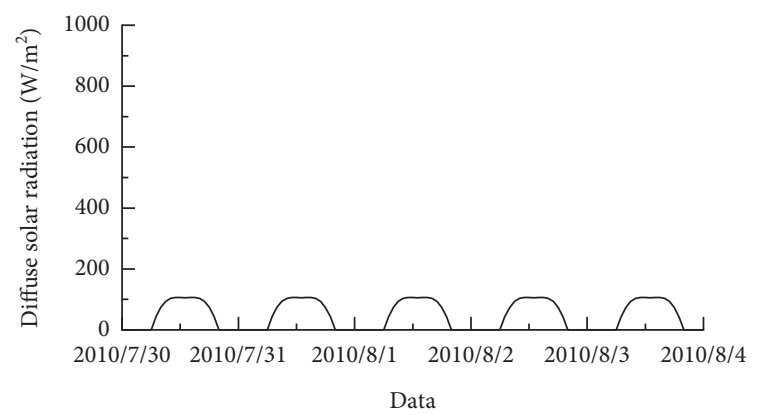

(d)

FiguRe 9: Hourly environmental records for the period from July 30 to August 3, 2010: (a) air temperature, (b) wind speed, (c) direct solar radiation, and (d) diffuse solar radiation.

TABLE 1: Material properties.

\begin{tabular}{lcc}
\hline Parameters & Concrete & Asphalt concrete \\
\hline Density, $\rho\left(\mathrm{kg} / \mathrm{m}^{3}\right)$ & 2500 & 2100 \\
Specific heat capacity, $c\left(\mathrm{~J} / \mathrm{kg} \cdot{ }^{\circ} \mathrm{C}\right)$ & 980 & 1170 \\
Thermal conductivity, $k\left(\mathrm{~W} / \mathrm{m} \cdot{ }^{\circ} \mathrm{C}\right)$ & 2.4 & 0.98 \\
Absorptivity, $\alpha$ & 0.65 & 0.9 \\
Emissivity, $\varepsilon_{0}$ & 0.88 & 0.95 \\
\hline
\end{tabular}

along the web and bottom slab (0.5A-A line $+0.5 \mathrm{~B}-\mathrm{B}$ line$+\mathrm{C}-\mathrm{C}$ line, see Figure 11) and the transverse temperature distributions along the web (D-D line, see Figure 11) were studied and compared.

Figure 12 shows the predicted vertical temperature distributions along the depth of the girder at sections T1 and T2 for the four sunny days when the vertical temperature differences were maximum. The vertical temperature difference was equal to the temperature difference between the maximum and minimum temperatures in the deck and web. It can be seen from the figure that the maximum vertical temperature differences in the web of section $\mathrm{T} 1$ for the four sunny days were $14.4^{\circ} \mathrm{C}, 15.2^{\circ} \mathrm{C}$, $13.1^{\circ} \mathrm{C}$, and $15.9^{\circ} \mathrm{C}$, respectively, while those for section $\mathrm{T} 2$ were $13.4^{\circ} \mathrm{C}, 13.0^{\circ} \mathrm{C}, 11.7^{\circ} \mathrm{C}$, and $13.8^{\circ} \mathrm{C}$, respectively. The differences between the measured temperature distributions and the predicted temperature distributions were all small, and the predicted temperature distribution shapes for the four sunny days were all similar. The highest temperatures all appeared on the top surface of the deck and then decreased rapidly through the upper part of the girder, reaching a minimum at a depth of approximately
$1.5 \mathrm{~m}$. The temperatures were almost constant after reaching a depth of approximately $1.5 \mathrm{~m}$ until reaching the top surface of the bottom slab. Due to the heat from the surrounding air and reflected radiation from the ground, the highest temperatures in the bottom slab all appeared on the outer surface and then decreased rapidly through the thickness of the bottom slab, reaching a minimum near the inner surface. However, the minimum temperatures in the bottom slab of section T1 were all lower than its web temperatures, while the minimum temperatures in the bottom slab of section T2 were all nearly equal to its web temperatures.

Figure 13 shows the predicted transverse temperature distributions along the web of the girder at sections $\mathrm{T} 1$ and T2 for the four sunny days when the temperatures on the outer surface of the web reached their maximum values. As shown, the differences between the measured temperature distributions and the predicted temperature distributions were all small. However, the measured temperatures in the eastern web were not recorded due to errors; therefore, the measured temperature distributions and the predicted temperature distributions in the eastern web could not be compared. The predicted temperature distribution shapes for the four sunny days were all similar. The highest temperatures in sections T1 and T2 all appeared on the outer surface of the western web. The maximum transverse temperature differences in the web of section T1 were all greater than those in the web of section T2. The main reason for this is that the web of section $\mathrm{T} 1$ could receive more solar radiation than section $\mathrm{T} 2$. The maximum transverse temperature differences in the western web were all greater than 

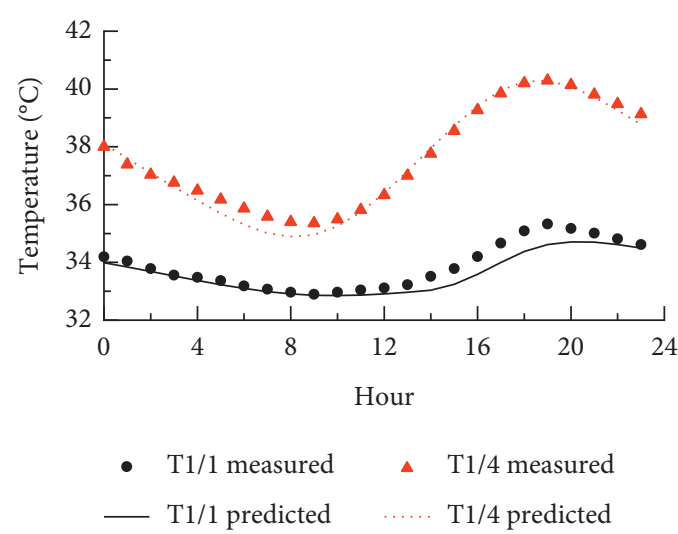

(a)
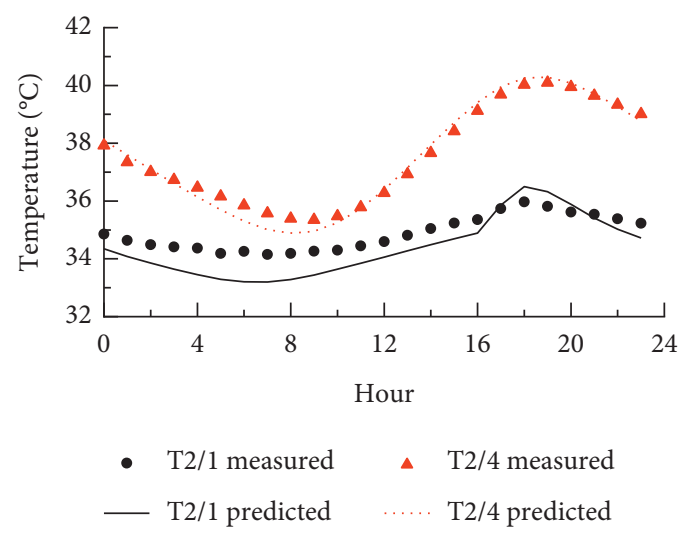

(c)

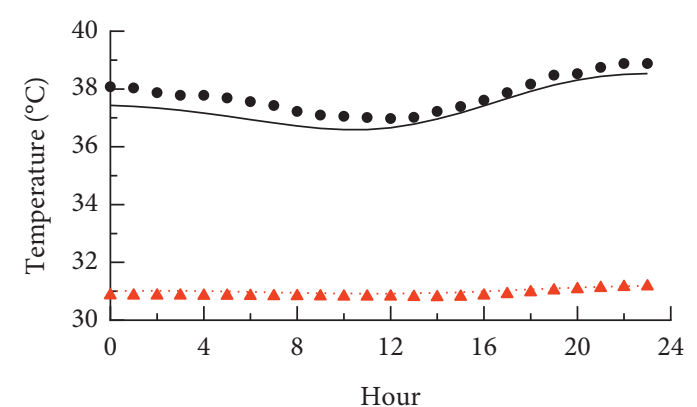

- T1/07 measured $\quad \Delta \quad \mathrm{T} 1 / 19$ measured

— T1/07 predicted $\quad \ldots . . . \mathrm{T} 1 / 19$ predicted

(b)

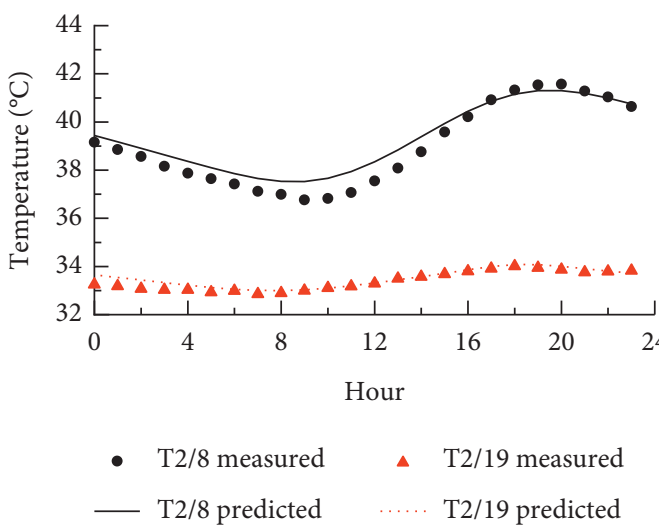

(d)

Figure 10: Comparison of the measured and predicted temperatures: (a) T1/2 and T1/4, (b) T1/7 and T1/19, (c) T2/2 and T2/4, and (d) T2/8 and T2/19.

TABLE 2: Weather conditions of the four sunny days.

\begin{tabular}{lcccc}
\hline Data & Weather & Maximum air temperature $\left({ }^{\circ} \mathrm{C}\right)$ & Minimum air temperature $\left({ }^{\circ} \mathrm{C}\right)$ & Average wind speed $(\mathrm{m} / \mathrm{s})$ \\
\hline June 7,2010 & Sunny & 20.7 & 20.1 & 3.0 \\
June 19, 2010 & Sunny & 32.1 & 23.2 & 3.5 \\
July 22, 2010 & Sunny & 34.0 & 28.0 & 4.7 \\
August 3, 2010 & Sunny & 37.6 & 32.0 & 2.7 \\
\hline
\end{tabular}

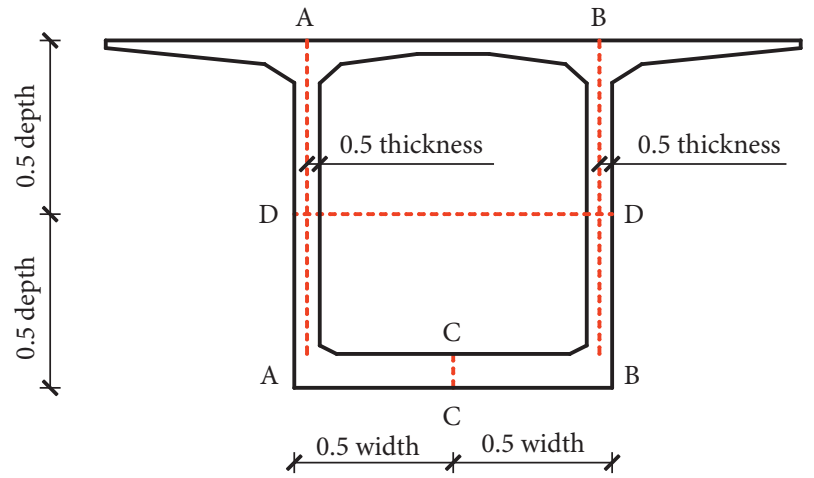

FIgURE 11: The calculated positions of vertical and transverse temperature distributions. those in the eastern web, and the maximum transverse temperature differences in the western web of section $\mathrm{T} 1$ for the four sunny days were $9.9^{\circ} \mathrm{C}, 13.2^{\circ} \mathrm{C}, 9.2^{\circ} \mathrm{C}$, and $11.0^{\circ} \mathrm{C}$, respectively, while those in section $\mathrm{T} 2$ were $6.7^{\circ} \mathrm{C}, 8.1^{\circ} \mathrm{C}$, $5.6^{\circ} \mathrm{C}$, and $6.0^{\circ} \mathrm{C}$, respectively.

From Figures 12 and 13, it can be concluded that the temperature distribution shapes in the girder for the four sunny days were all similar, but the girder size has a great influence on the vertical and transverse temperature distributions in the girder, and this topic should be carefully studied. To study the effect of the girder size on the temperature distribution of the CBG, thermal analyses of another four cross-sections, which are called T3, T4, T5, and T6, respectively, were carried out. The fourth sunny day was selected for analysis. The locations and some characteristic dimensions of the six cross-sections are shown in Figure 14. 


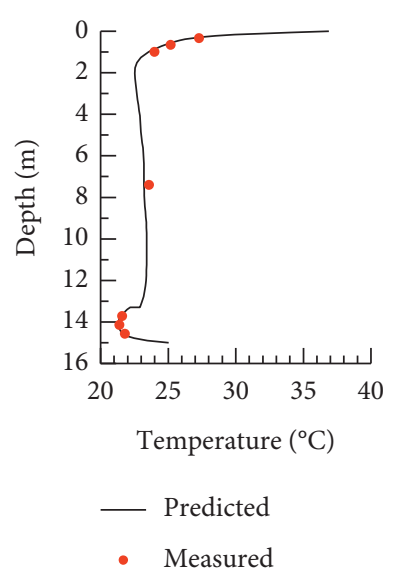

(a)

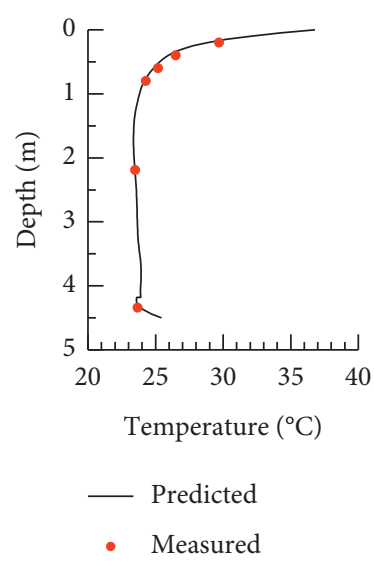

(e)

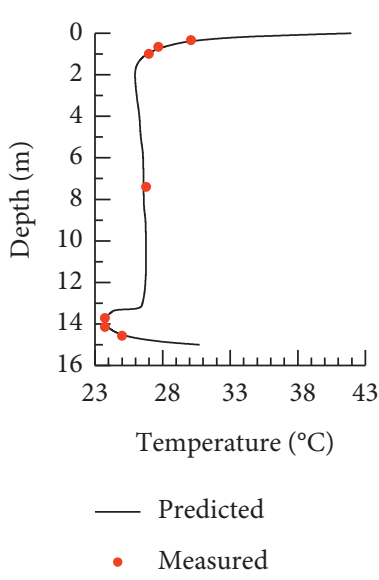

(b)

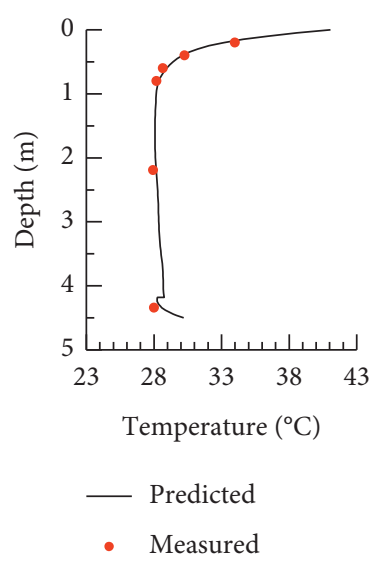

(f)

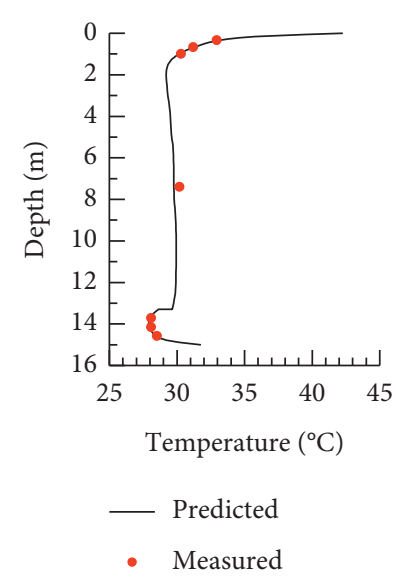

(c)

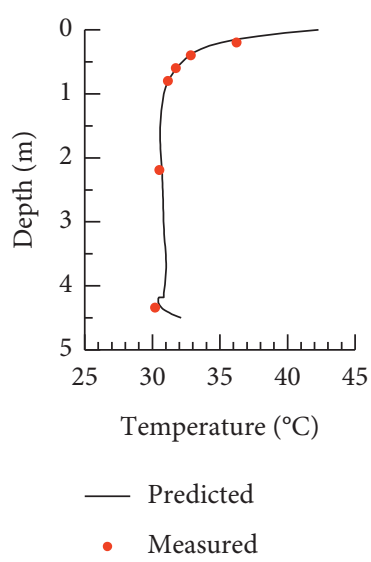

(g)

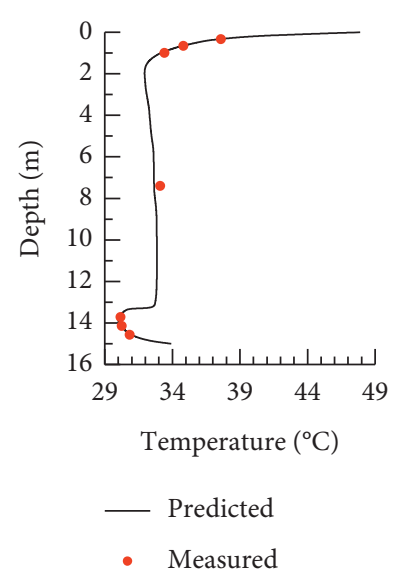

(d)

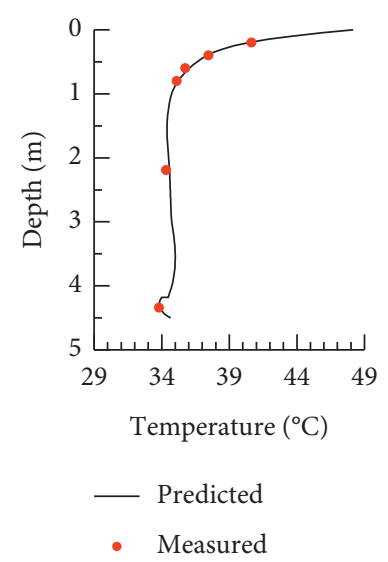

(h)

FIgURE 12: The predicted vertical temperature distributions along the depth of the girder for the four sunny days: (a) section T1 on June 7, 2010; (b) section T1 on June 19, 2010; (c) section T1 on July 22, 2010; (d) section T1 on August 3, 2010; (e) section T2 on June 7, 2010; (f) section T2 on June 19, 2010; (g) section T2 on July 22, 2010; (d) section T2 on August 3, 2010.

The predicted vertical temperature distributions along the depth of the girder at the six cross-sections on August 3, 2010, when the vertical temperature differences reached a maximum value, are depicted in Figure 15. According to the figure, the temperature profiles in the deck, web, and bottom slab of the six sections all exhibited similar shapes. The temperatures in the deck of the six sections were almost the same. However, the temperatures in the webs were dependent on their thicknesses; the thicker the web, the lower the temperature would be. The maximum temperature difference between the webs was $2.5^{\circ} \mathrm{C}$. The temperatures on the outer surface of the bottom slabs were almost the same, but the minimum temperatures in the bottom slabs were also dependent on their thicknesses; the thicker the bottom slab, the lower the minimum temperature would be. The maximum temperature difference between the minimum temperatures in the bottom slab was $3.9^{\circ} \mathrm{C}$. Further analysis showed that the temperature in the webs and the minimum temperature in the bottom slabs all varied almost linearly with their thicknesses.

Table 3 shows the predicted maximum vertical temperature difference and its equivalent linear temperature difference in the girder at the six cross-sections. The equivalent linear temperature difference can be calculated using the following equation:

$$
\Delta T_{y}=\frac{1}{I_{x}} \iint_{A} T(y) y \mathrm{~d} A,
$$

where $\Delta T_{y}$ is the equivalent linear temperature difference (ELTD), $I_{x}$ is the moment of inertia of the section about the $x$-axis, $T(y)$ is the temperature gradient at depth $y$ from the outer surface of the deck, and $A$ is the cross-sectional area of the girder. As shown in Table 3, if the temperature gradient in the bottom slab is ignored, the equivalent linear temperature difference in the girder would be underestimated. When the bottom slab thickness is greater than $0.6 \mathrm{~m}$, the values of the underestimations were more than $20.8 \%$, which would result in a substantial underestimation of the temperature-induced stresses and deflections.

Figure 16 depicts the predicted transverse temperature distributions along the web of the girder at the six crosssections on August 3, 2010, when the temperatures on the outer surface of the web reached a maximum value. As shown, the maximum temperatures on the outer surface of 

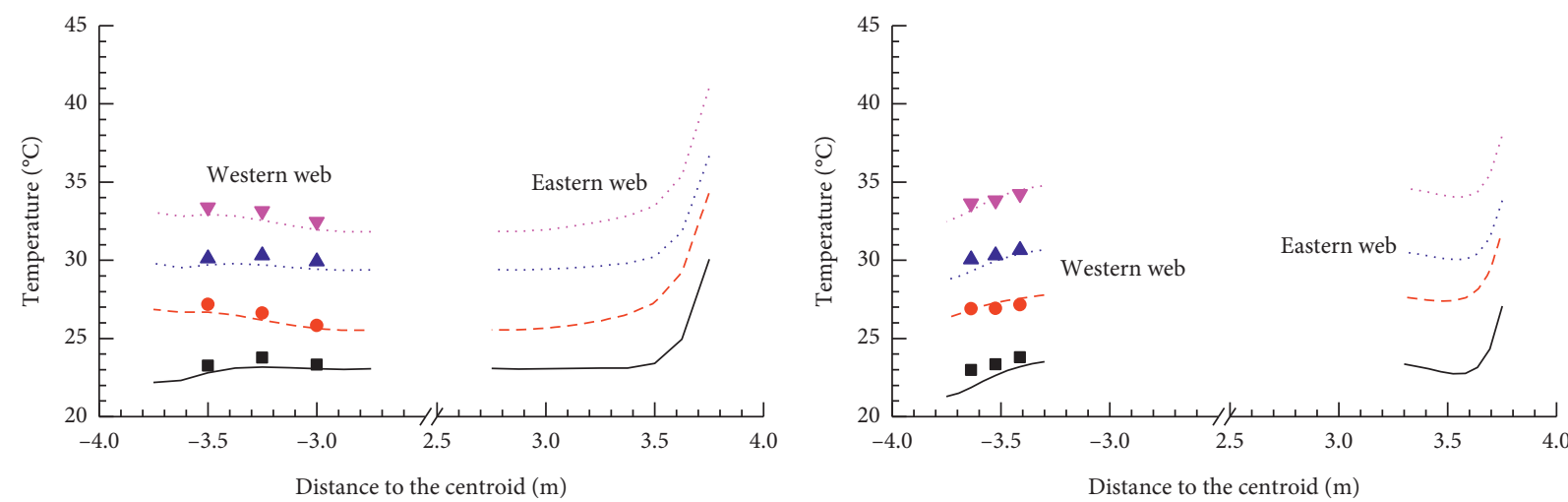

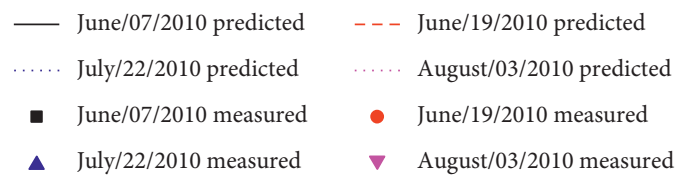

(a)

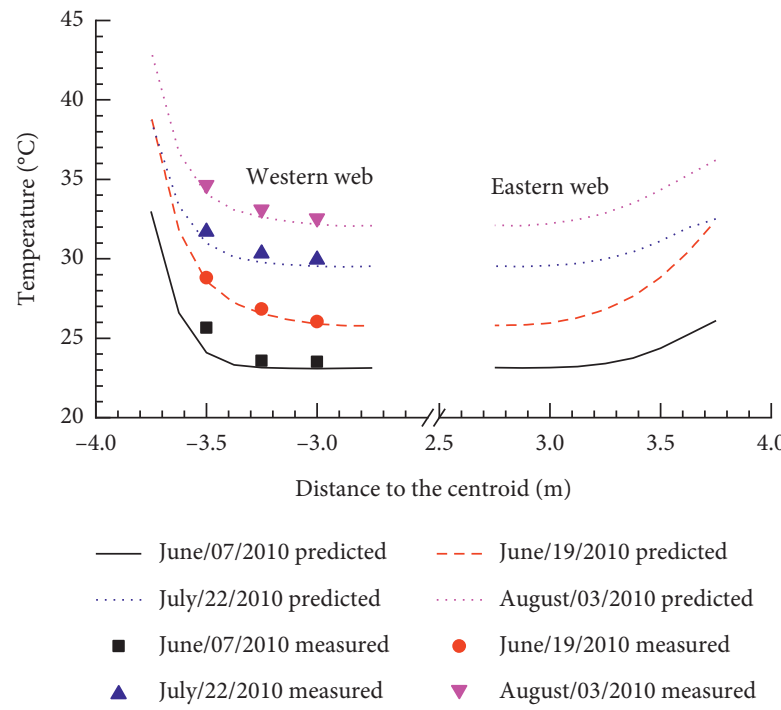

(c)

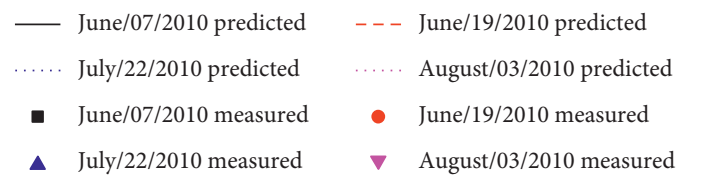

(b)

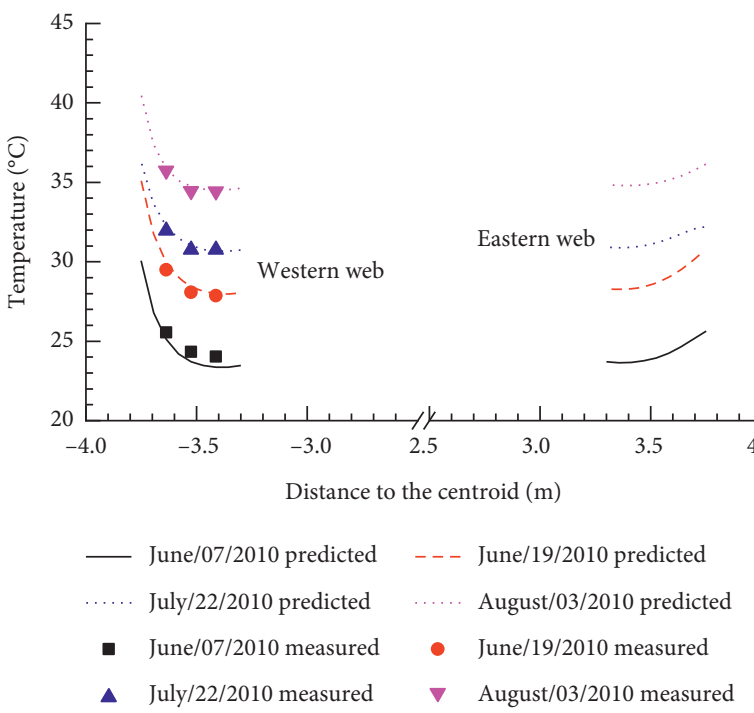

(d)

FIGURE 13: The predicted transverse temperature distributions along the web of the girder for the four sunny days: (a) section T1 and the temperature on the outer surface of the eastern web reached a maximum value; (b) section T2 and the temperature on the outer surface of the eastern web reached a maximum value; (c) section $\mathrm{T} 1$ and the temperature on the outer surface of the western web reached a maximum value; (d) section T2 and the temperature on the outer surface of the western web reached a maximum value.

the webs at the six cross-sections, except section T2, were almost equal. This phenomenon indicated that the cantilever slabs of girders except the girders near the midspan were not long enough to protect the web from solar radiation. When the maximum temperatures appeared on the outer surface of the eastern webs, the transverse temperature differences in the western webs were all small, and vice versa. The temperatures on the inner surface of the webs at the same section were nearly equal, and all temperatures depended on their thicknesses; the thicker the web, the lower the minimum temperature would be. Further analysis shows that the minimum temperatures in the webs varied almost linearly with their thicknesses.

\section{Recommendations for Temperature Gradient Models in the Long-Span PCBG Bridge}

6.1. Temperature Gradient Models. For design purposes, simplified vertical and transverse temperature gradient models that can consider changes along the longitudinal direction of the long-span PCBG bridge were proposed on the basis of the results described earlier. The proposed vertical temperature gradient model is shown in Figure 17(a), and the notations are defined as follows.

(1) $T_{\mathrm{d}}$ is the temperature on the top surface of the deck and is kept constant along the longitudinal direction of the bridge. $T_{\mathrm{d}}\left(y_{\mathrm{d}}\right)$ is the continuous temperature 

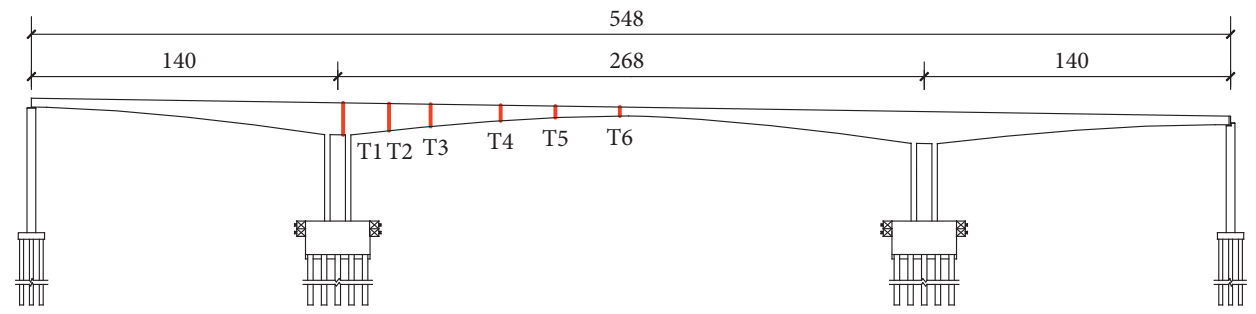

(a)

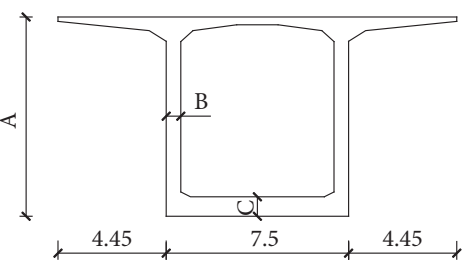

\begin{tabular}{lcccccc}
\hline Size & T1 & T2 & T3 & T4 & T5 & T6 \\
\hline A & 15 & 4.5 & 13.1 & 10.9 & 8.1 & 6.15 \\
B & 1 & 0.45 & 0.7 & 0.6 & 0.6 & 0.5 \\
C & 1.7 & 0.32 & 1.4 & 1.16 & 0.79 & 0.54 \\
\hline
\end{tabular}

(b)

FIGURE 14: Information for the six cross-sections: (a) locations and (b) characteristic dimensions (unit: m).

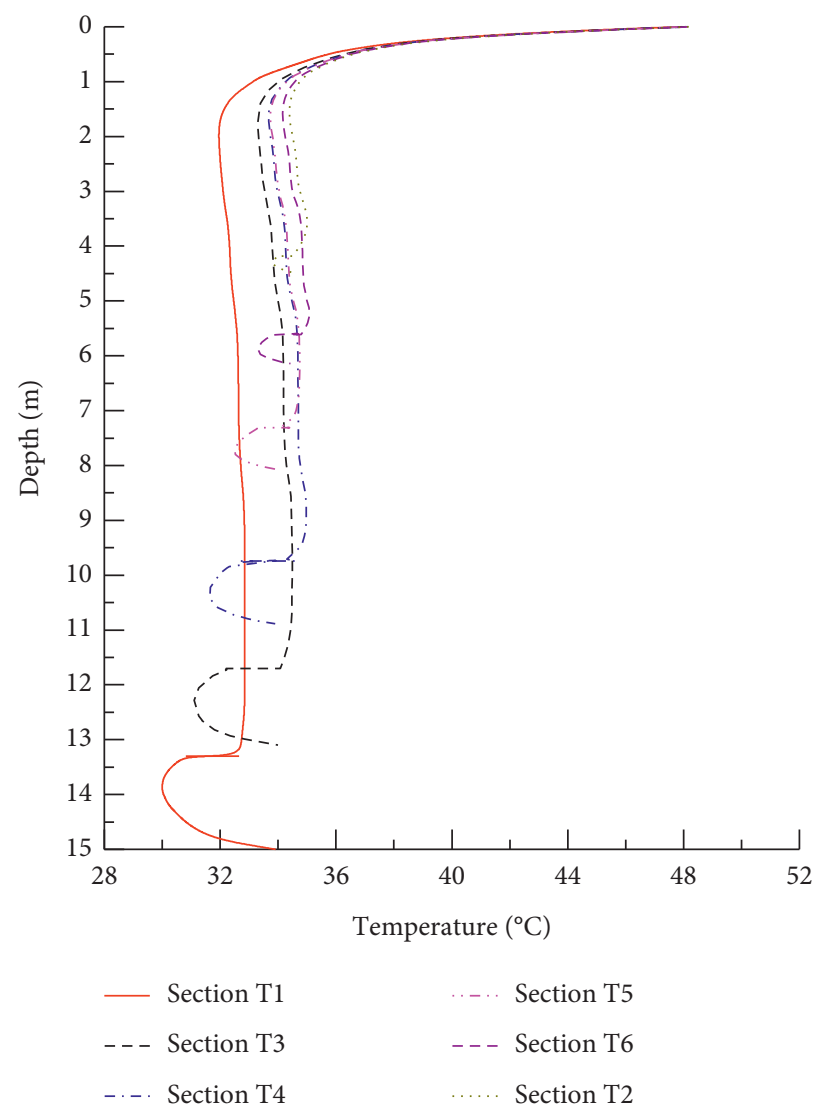

FiguRE 15: The predicted vertical temperature distributions along the depth of the girder at the six cross-sections on August 3, 2010, when the vertical temperature differences reached a maximum value. 
TABLE 3: The predicted maximum vertical temperature difference and its equivalent linear temperature difference in the girder at the six cross-sections.

\begin{tabular}{lcccc}
\hline Section & $\begin{array}{c}\text { Vertical temperature difference } \\
\left({ }^{\circ} \mathrm{C}\right)\end{array}$ & $\begin{array}{c}\text { ELTD } \\
\left({ }^{\circ} \mathrm{C}\right)\end{array}$ & $\begin{array}{c}\text { ELTD (ignore the temperatures in the bottom } \\
\text { slab) }\left({ }^{\circ} \mathrm{C}\right)\end{array}$ & $\begin{array}{c}\text { Difference between the two } \\
\text { ELTD }(\%)\end{array}$ \\
\hline T1 & 16.0 & 6.4 & 4.5 & 29.7 \\
T3 & 14.8 & 8.9 & 5.7 & 36.0 \\
T4 & 14.4 & 7.3 & 4.6 & 37.0 \\
T5 & 14.4 & 7.2 & 5.7 & 20.8 \\
T6 & 14.0 & 7.3 & 6.0 & 17.8 \\
T2 & 13.8 & 7.8 & 7.3 & 6.4 \\
\hline
\end{tabular}

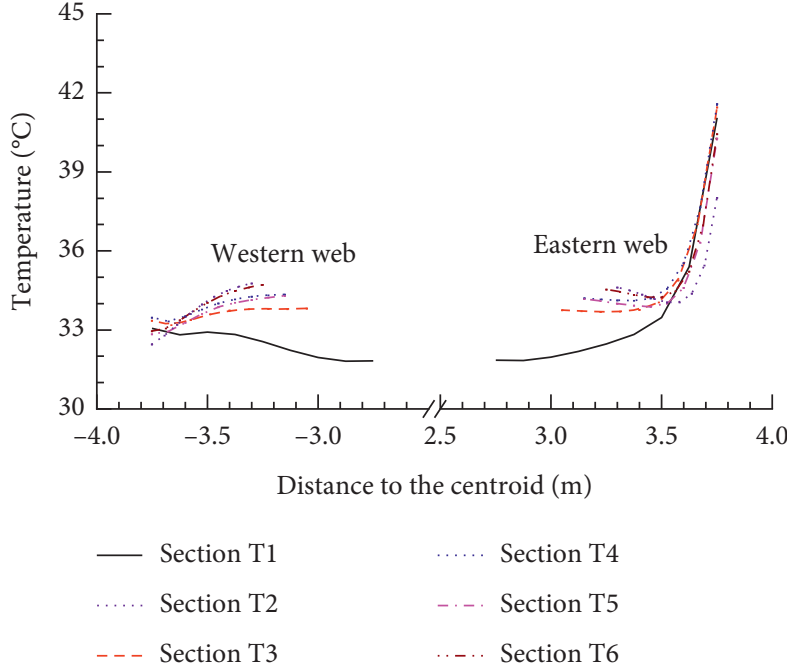

(a)

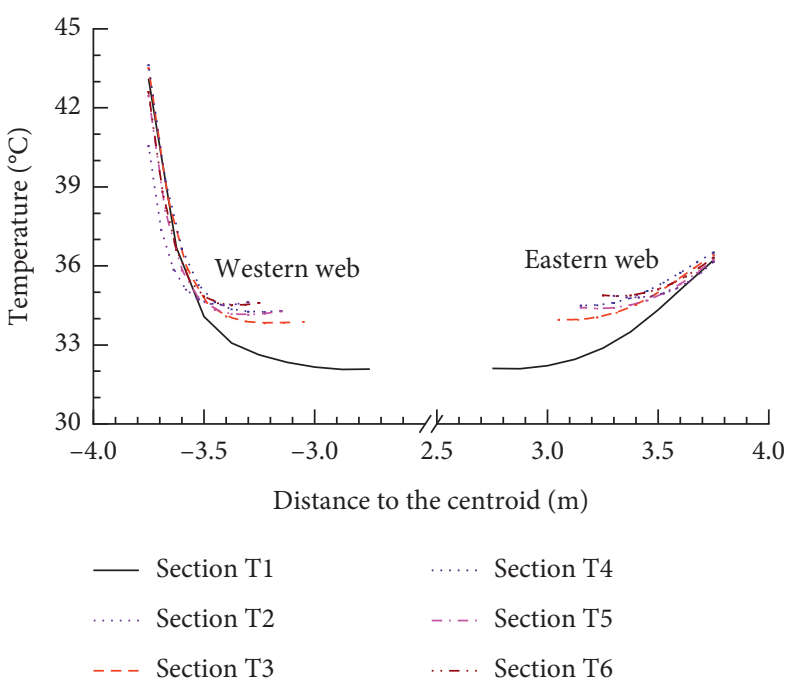

(b)

Figure 16: The predicted transverse temperature distributions along the web of the girder at the six cross-sections on August 3, 2010, when the temperatures on the outer surface of the web reached a maximum value: (a) eastern web; (b) western web.

distribution decreasing from $T_{\mathrm{d}}$ on the top surface of the deck to $T_{\mathrm{w}}$ in the web and can be expressed as follows:

$$
\begin{aligned}
T_{\mathrm{d}}\left(y_{\mathrm{d}}\right) & =T_{\mathrm{w}}+\left(T_{\mathrm{d}}-T_{\mathrm{w}}\right) e^{-4 y_{\mathrm{d}}}, \\
T_{\mathrm{w}} & =\left(\frac{d_{\mathrm{wi}}-d_{\mathrm{wp}}}{d_{\mathrm{wm}}-d_{\mathrm{wp}}}\right) T_{\mathrm{wm}},
\end{aligned}
$$

where $d_{\mathrm{wp}}, d_{\mathrm{wm}}$, and $d_{\mathrm{wi}}$ are the web thicknesses of the cross-section at the intermediate pier, midspan, and other locations, respectively, and $T_{\mathrm{wm}}$ is the temperature in the web of the cross-section at the midspan.

(2) $T_{\mathrm{b}}$ is the temperature on the outer surface of the bottom slab and is also kept constant along the longitudinal direction of the bridge. $T_{\mathrm{b}}\left(y_{\mathrm{b}}\right)$ is the continuous temperature distribution decreasing from $T_{\mathrm{b}}$ on the outer surface of the bottom slab to $T_{\mathrm{bt}}$ on the inner surface and can be calculated by

$$
\begin{gathered}
T_{\mathrm{b}}\left(y_{\mathrm{b}}\right)=T_{\mathrm{bt}}+\left(T_{\mathrm{b}}-T_{\mathrm{bt}}\right)\left(\frac{d_{\mathrm{b}}-y_{\mathrm{b}}}{d_{\mathrm{b}}}\right)^{5}, \\
T_{\mathrm{bt}}=T_{\mathrm{btp}}+\left(\frac{d_{\mathrm{b} i}-d_{\mathrm{bp}}}{d_{\mathrm{bm}}-d_{\mathrm{bp}}}\right)\left(T_{\mathrm{btm}}-T_{\mathrm{btp}}\right),
\end{gathered}
$$

where $d_{\mathrm{bp}}, d_{\mathrm{bm}}$, and $d_{\mathrm{bi}}$ are the bottom slab thicknesses of the cross-section at the intermediate pier, midspan, and the other locations, respectively, and $T_{\mathrm{btp}}$ and $T_{\mathrm{btm}}$ are the temperatures on the inner surface of the bottom slab at the intermediate pier and midspan, respectively.

Figure 17(b) shows the proposed transverse temperature gradient model. For the temperature gradient, only the temperature in the web is taken into consideration. The notations are defined as follows:

(1) $T_{1}$ is the temperature on the outer surface of the web and is kept constant along the longitudinal direction of the bridge. $T_{0}$ is the minimum temperature in the 


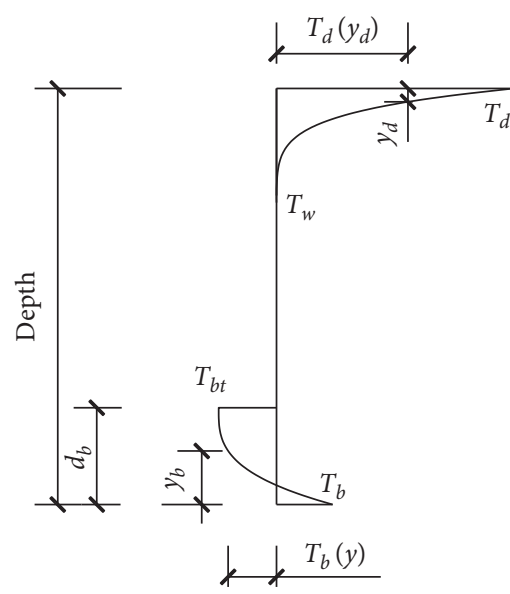

(a)

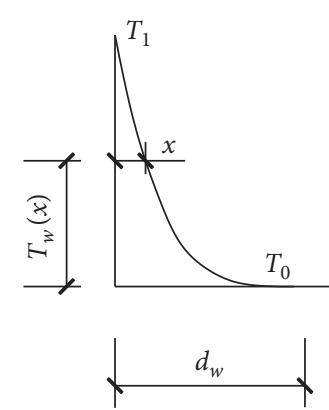

(b)

Figure 17: The proposed (a) vertical and (b) transverse temperature gradient models of the long-span PCBG bridge.

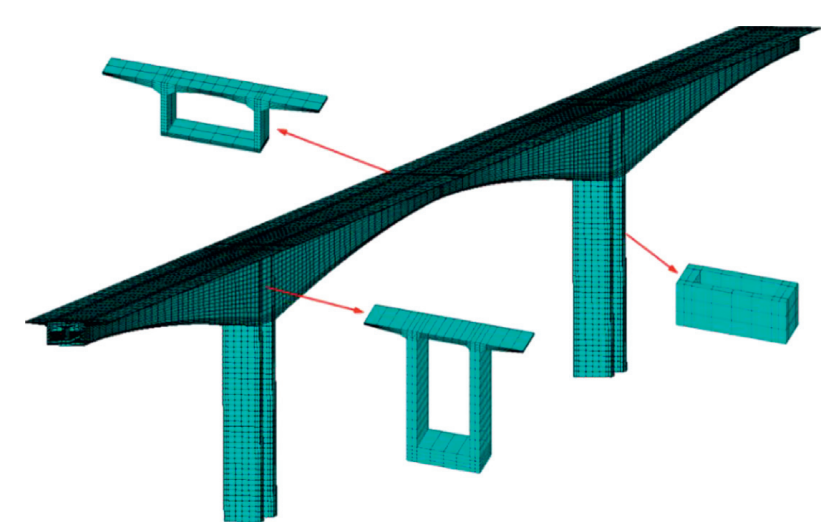

FIGURE 18: FEM of the auxiliary shipping channel bridge of the SuTong Bridge.

webs. The value of $T_{0}$ depends on the web thickness and can be calculated by

$$
T_{0}=\left(\frac{d_{\mathrm{w} i}-d_{\mathrm{wp}}}{d_{\mathrm{wm}}-d_{\mathrm{wp}}}\right) T_{0 \mathrm{~m}},
$$

where $T_{0 \mathrm{~m}}$ is the temperature on the inner surface of the web at the midspan.

(2) $T_{\mathrm{w}}(x)$ is the continuous temperature distribution in the web and can be calculated by the following equation:

$$
T_{\mathrm{w}}(x)=T_{0}+\left(T_{1}-T_{0}\right)\left(\frac{d_{\mathrm{w} i}-x}{d_{\mathrm{w} i}}\right)^{5},
$$

6.2. Validation of the Recommended Temperature Gradient Models. The structural response of the bridge to the temperature gradient was determined using a 3D solid FEM (see Figure 18). The SOLID186 element, which is a higher order 3D 20-node solid element that exhibits quadratic displacement behaviour, was adopted. The deck, web, and bottom slab were meshed with five, two, and four elements through their thicknesses, respectively. The web was meshed with twelve elements along the depth of the girder, and the deck and bottom slab were meshed with twenty and eight elements along the width of the girder, respectively. At the side piers, the nodes on the bottom surface of the girder were fixed in the vertical and lateral directions, while the nodes on the bottom surface of all the piers were fixed in all directions. The thermal expansion coefficient of the concrete was computed as the slope of the least-square line relating the measured strains to the temperature of the nonstress strain sensors. The average thermal expansion coefficient calculated by this method was $10.06 \mu \varepsilon /{ }^{\circ} \mathrm{C}$ for the concrete. The density, Young's modulus, and Poisson's ratio for the concrete were $2500 \mathrm{~kg} / \mathrm{m}^{3}, 36.5 \mathrm{GPa}$, and 0.2 , respectively.

The validation of the model was verified by a comparison of the measured curvatures and FEM-computed curvatures using the predicted maximum temperature gradients on August 3, 2010. The measured curvatures were calculated from the slope of the line through the section depth or width fitting the short-term changes in the total strain. For the predicted maximum vertical temperature gradients, the parameter values of $T_{\mathrm{d}}, T_{\mathrm{wm}}, T_{\mathrm{btp}}, T_{\mathrm{btm}}$, and $T_{\mathrm{b}}$ were $15.9^{\circ} \mathrm{C}$, $2.5^{\circ} \mathrm{C},-2.0^{\circ} \mathrm{C}, 1.9^{\circ} \mathrm{C}$, and $4.0^{\circ} \mathrm{C}$, respectively, while for the transverse temperature gradient model, $T_{1}$ and $T_{0 \mathrm{~m}}$ were $11.0^{\circ} \mathrm{C}$ and $2.5^{\circ} \mathrm{C}$, respectively. Figure 19 shows the comparison of the measured curvatures and FEM-computed curvatures. As shown, the FEM-computed curvatures and measured curvatures closely matched for the two sections.

\section{Effects of the Temperature Gradients on the Long-Span PCBG Bridge}

7.1. Effects of the Vertical Temperature Gradients on the LongSpan PCBG Bridge. Based on the FEM of the auxiliary shipping channel bridge of the SuTong Bridge, the deformations and stresses derived from the proposed temperature gradient model and the temperature gradient model according to four codes were studied and compared. Four bridge design codes (see Figure 20), including the China 


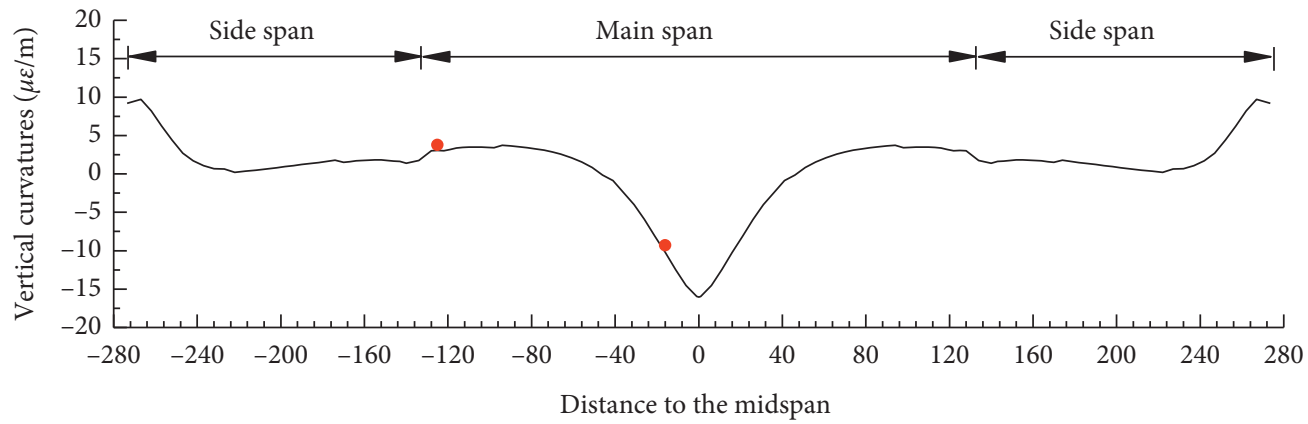

- FEM-computed curvatures

- Measured curvatures

(a)

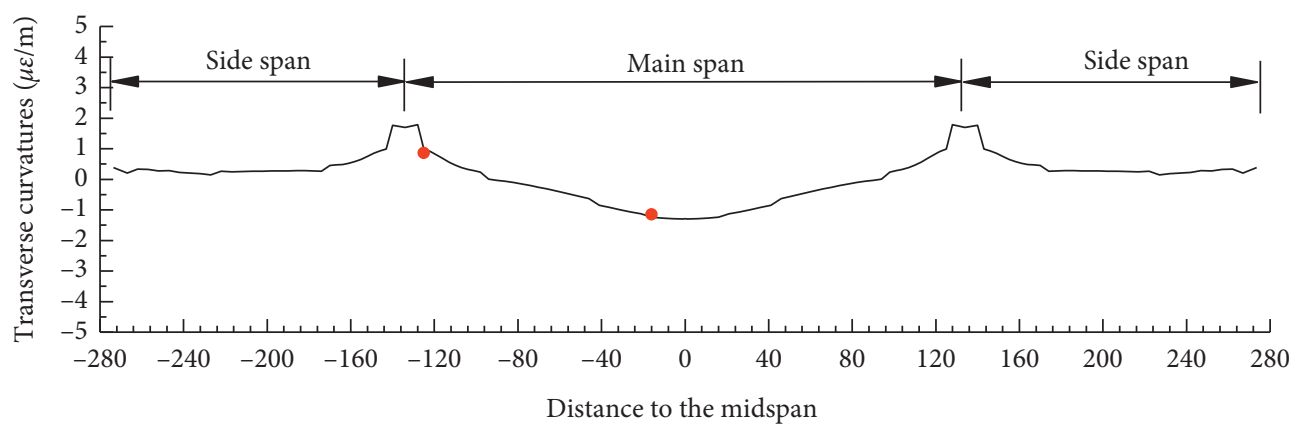

FEM-computed curvatures

- Measured curvatures

(b)

FIGURE 19: Comparisons of the measured and FEM-computed curvatures: (a) vertical curvatures and (b) transverse curvatures.

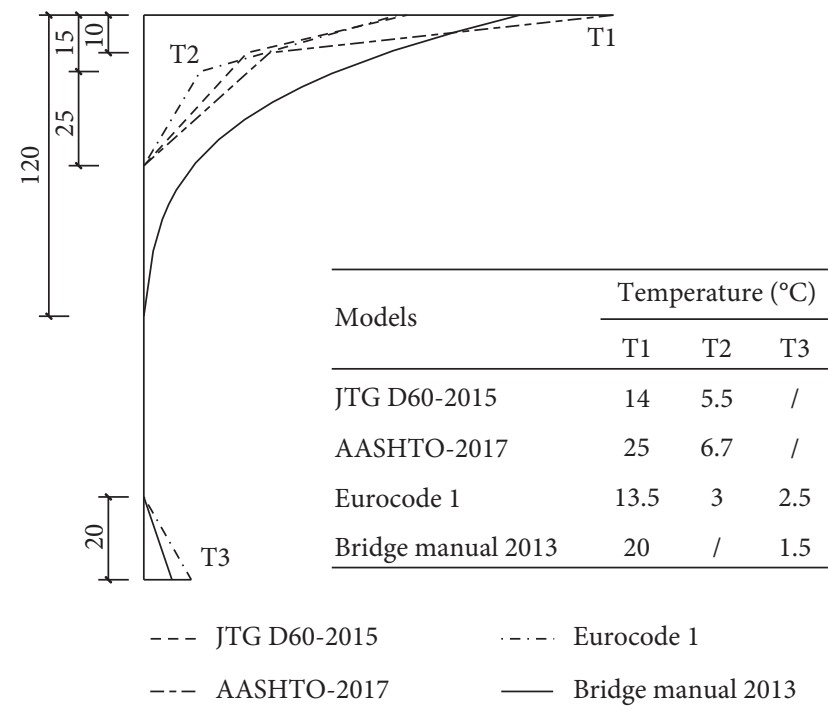

Figure 20: Vertical temperature gradient model (unit: $\mathrm{cm}$ ).

general design specification for highway bridges and culverts (JTG D60-2015) [27], AASHTO LRFD Bridge Design Specifications (AASHTO 2017) [28], the New Zealand Bridge Specification (Bridge manual 2013) [29], and
Eurocode 1 [30], were selected. The predicted maximum vertical temperature gradients on August 3, 2010, were used. For comparison purposes, the temperature differences in the deck of the four codes were all set to $14.7^{\circ} \mathrm{C}$, which was the average temperature difference in the deck of the proposed model. Therefore, the temperature gradients in the four codes were all multiplied by a corresponding coefficient.

Figure 21 shows the vertical deformations derived from the proposed model and the model according to the four codes. As shown, the shapes of the vertical deformations were similar; the girders of the side spans produced upward deformations, while the girders of the main span produced downward deformations. The maximum values of the deformations in the side span were very small and varied from $1.99 \mathrm{~mm} \sim 3.36 \mathrm{~mm}$; however, the maximum values of the deformations in the main span were very large. The maximum deformations in the main span of the proposed model and the models proposed in JTG D60-2015, AASHTO 2017, Bridge manual 2013, and Eurocode 1 were $32.39 \mathrm{~mm}$, $16.37 \mathrm{~mm}, 13.13 \mathrm{~mm}, 23.20 \mathrm{~mm}$, and $12.89 \mathrm{~mm}$, respectively. The temperature gradient models of the four codes all underestimated the maximum deformations in the main span. The two main reasons for this phenomenon were that the temperature gradients in the deck for the four codes decreased faster than that of the proposed model, and the 


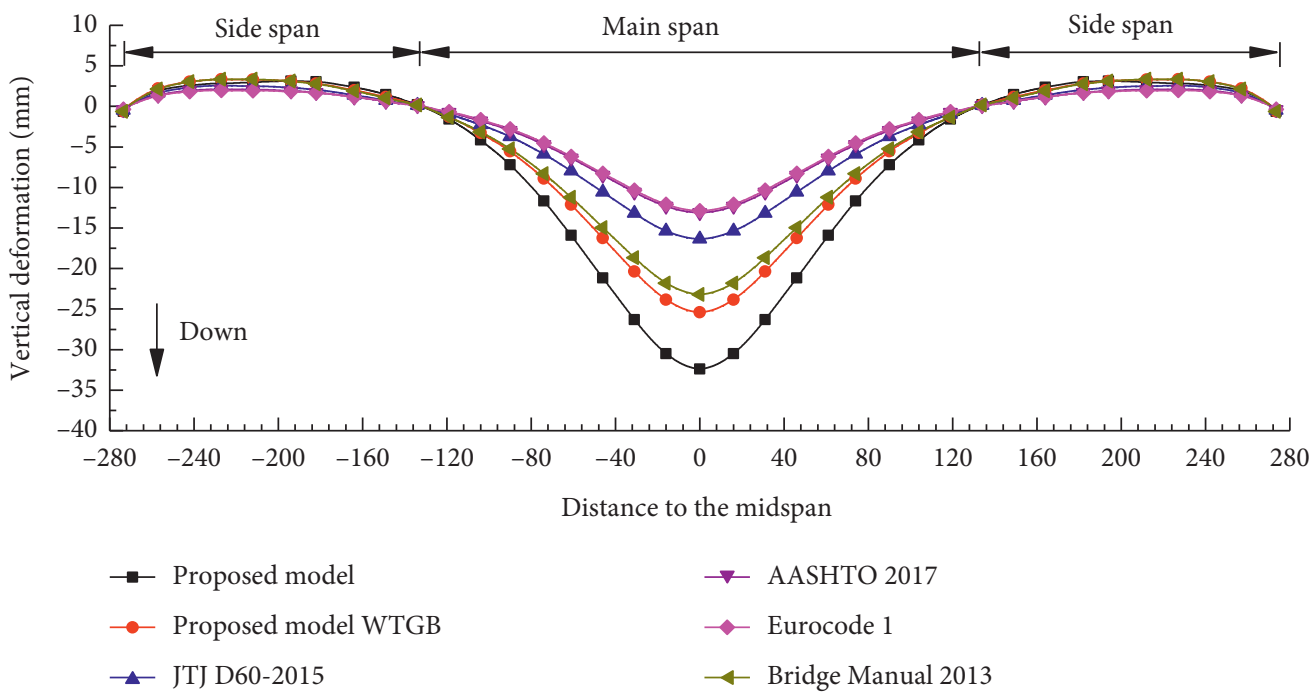

FIgURE 21: Comparison of the vertical deformations.

TABLE 4: Comparison of the MMLS in the deck and bottom slab (unit: MPa).

\begin{tabular}{lcccc}
\multirow{2}{*}{ Temperature gradient model } & \multicolumn{2}{c}{ Section S2 } & \multicolumn{2}{c}{ Section T2 } \\
& MMLS in the deck & MMLS in the bottom slab & MMLS in the deck & MMLS in the bottom slab \\
\hline Proposed model & $0.49,-5.09$ & $0.62,-1.83$ & $0.07,-5.21$ & $2.95,2.32$ \\
JTG D60-2015 & $1.01,-5.91$ & $0.02,-0.08$ & $0.77,-5.96$ & $1.80,1.43$ \\
AASHTO 2017 & $0.78,-6.06$ & $0.02,-0.07$ & $0.59,-6.09$ & $1.45,1.14$ \\
Bridge Manual 2013 & $0.72,-5.43$ & $0.10,-0.68$ & $0.53,-5.55$ & $2.37,1.73$ \\
Eurocode 1 & $1.27,-6.01$ & $0.19,-0.83$ & $1.04,-5.95$ & $1.43,0.37$ \\
\hline
\end{tabular}

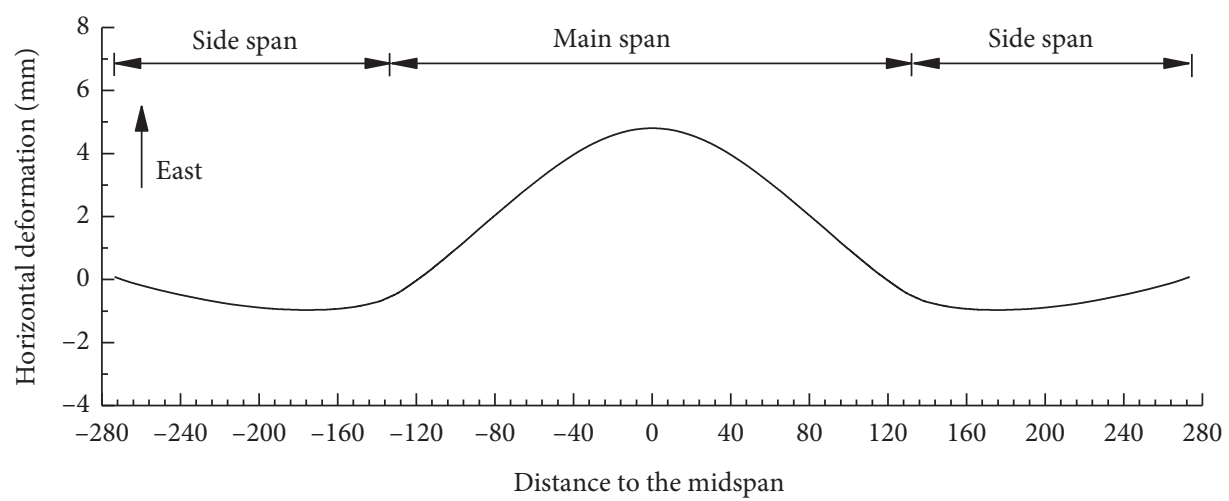

FIgURE 22: Horizontal deformation.

TABLE 5: MMTS in the deck, webs, and bottom slab (unit: MPa).

\begin{tabular}{lccr}
\hline Cross-section & MMTS in the web & MMTS in the deck & MMTS in the bottom slab \\
\hline Section S2 & $1.20,-2.94$ & $0.25,-0.48$ & $0.25,-0.25$ \\
Section T2 & $0.96,-1.60$ & $0.44,-0.44$ & $0.55,-0.55$ \\
\hline
\end{tabular}

four codes do not consider the negative temperature gradients in the bottom slab. As mentioned in Table 3, ignoring the temperature gradient in the bottom slab will lead to a substantial underestimation of the deflection.
Table 4 depicts the maximum and minimum longitudinal stresses (MMLS) in the deck and bottom slab derived from the proposed model and the model according to the four codes, respectively. It can be seen from the table that the 
four codes all underestimated the longitudinal stress in the bottom slab. It is worth noting that the maximum longitudinal stresses in the bottom slab near the midspan were very large and could be compared to the tensile strength of the concrete. Therefore, the stress caused by the vertical temperature gradient could be one of the major factors that cause cracking, and the temperature gradient in the bottom should not be ignored.

\subsection{Effects of the Transverse Temperature Gradient on the} Long-Span PCBG Bridge. For the four codes, only Eurocode 1 notes that substantial temperature differences can occur between the inner and outer web walls of large PCBG bridges, and $15^{\circ} \mathrm{C}$ may be recommended as a linear temperature difference between the inner and outer web walls. However, Eurocode 1 does not provide transverse temperature gradient distributions. Therefore, only the transverse deformations and transverse stresses derived from the proposed model are analysed in this section.

The horizontal deformations derived from the proposed model are shown in Figure 22. As shown, the values of the horizontal deformations induced by the transverse temperature gradient were much less than the values of the vertical deformations induced by the vertical temperature gradient. The side span and main span were deformed in opposite directions, and the maximum deformations of the side span and main span were $0.97 \mathrm{~mm}$ and $4.81 \mathrm{~mm}$, respectively.

Table 5 depicts the MMTS in the deck, webs, and bottom slab derived from the proposed model. As shown, the MMTS values in the deck and bottom slab were all small, while those in the web were relatively large. The MMTS values in the web near the intermediate pier were all greater than those near the midspan. The maximum transverse tensile stresses in the web near the intermediate pier and midspan were $1.20 \mathrm{MPa}$ and $0.96 \mathrm{MPa}$, respectively. Therefore, the lack of consideration of the transverse temperature gradient may cause the web to easily crack, which is also in agreement with the crack inspections performed by the Swedish Road Administration [20].

\section{Conclusions}

In this paper, the temperature gradient and its effect on a long-span PCBG bridge were studied. From the results presented in this paper, the following conclusions are obtained:

(1) The critical temperature gradients in the girder all occurred on sunny days after a substantial warming trend for several days. The temperatures in the deck along the longitudinal direction of the long-span PCBG bridge were almost the same. However, the temperatures in the web and bottom slab were different from each other, and the longitudinal temperature difference in the web and bottom slab reached $5.4^{\circ} \mathrm{C}$ and $2.5^{\circ} \mathrm{C}$, respectively, according to the measured data.
(2) The minimum temperature in the bottom slab can be lower than the web temperature; if the temperature gradient in the bottom slab is ignored, the equivalent linear temperature difference in the girder will be underestimated. When the thickness of the bottom slab is greater than $0.6 \mathrm{~m}$, the values are underestimated by more than $20.8 \%$, which will lead to a substantial underestimation of the temperature-induced stresses and deflections.

(3) To accurately calculate the thermal behaviour of the long-span PCBG bridge, simplified vertical and transverse temperature gradients that can consider its changes along the longitudinal direction of the bridge were proposed.

(4) The temperature gradient models of JTG D60-2015, AASHTO 2017, Bridge Manual 2013, and Eurocode 1 all underestimated the maximum deformations and the maximum longitudinal stress in the bottom slab of the long-span PCBG bridges. The maximum longitudinal stress, which is caused by the vertical temperature gradients in the bottom slab near the midspan, is very large and can be compared to the tensile strength of concrete.

(5) The cantilever slab of the long-span PCBG bridge is not long enough to protect the web from solar radiation, except for the web near the midspan is protected; therefore, the lack of consideration of the transverse temperature gradient may cause the web to easily crack.

\section{Data Availability}

The data used to support the findings of this study are included within the article.

\section{Conflicts of Interest}

The authors declare that they have no conflicts of interest.

\section{Acknowledgments}

This research was supported by the National Natural Science Foundation of China (Grant no. 51641804), Natural Science Foundation of Jiangsu Province of China (Grant no. BK20160536), and Advanced Talents Scientific Research Foundation of Jiangsu University (Grant no. 15JDG170).

\section{References}

[1] Y. Xia, Y.-L. Xu, Z.-L. Wei, H.-P. Zhu, and X.-Q. Zhou, "Variation of structural vibration characteristics versus nonuniform temperature distribution," Engineering Structures, vol. 33, no. 1, pp. 146-153, 2011.

[2] J. B. Kennedy and M. H. Soliman, "Temperature distribution in composite bridges," Journal of Structural Engineering, vol. 113, no. 3, pp. 475-482, 1987.

[3] M. J. N. Priestley, "Design thermal gradients for concrete bridges," New Zealand Engineering, vol. 31, no. 9, pp. 213-219, 1976. 
[4] C. L. Roberts-Wollman, J. E. Breen, and J. Cawrse, "Measurements of thermal gradients and their effects on segmental concrete bridge," Journal of Bridge Engineering, vol. 7, no. 3, pp. 166-174, 2002.

[5] J. H. Lee, "Investigation of extreme environmental conditions and design thermal gradients during construction for prestressed concrete bridge girders," Journal of Bridge Engineering, vol. 17, no. 3, pp. 547-556, 2011.

[6] N. Tayşi and S. Abid, "Temperature distributions and variations in concrete box-girder bridges: experimental and finite element parametric studies," Advances in Structural Engineering, vol. 18, no. 4, pp. 469-486, 2015.

[7] S. R. Abid, N. Tayşi, and M. Özakça, "Experimental analysis of temperature gradients in concrete box-girders," Construction and Building Materials, vol. 106, pp. 523-532, 2016.

[8] S.-H. Kim, S.-J. Park, J. Wu, and J.-H. Won, “Temperature variation in steel box girders of cable-stayed bridges during construction," Journal of Constructional Steel Research, vol. 112, pp. 80-92, 2015.

[9] L. Zhou, Y. Xia, J. M. W. Brownjohn, and K. Y. Koo, "Temperature analysis of a long-span suspension bridge based on field monitoring and numerical simulation," Journal of Bridge Engineering, vol. 21, no. 1, Article ID 04015027, 2016.

[10] S. R. Abid, F. Mussa, N. Tayşi, and M. Özakça, "Experimental and finite element investigation of temperature distributions in concrete-encased steel girders," Structural Control and Health Monitoring, vol. 25, no. 1, Article ID e2042, 2018.

[11] J.-M. Lucas, M. Virlogeux, and C. Louis, "Temperature in the box girder of the normandy bridge," Structural Engineering International, vol. 15, no. 3, pp. 156-165, 2005.

[12] X. Lei, J. S. Ye, and Y. Wang, "Representative value of solar thermal difference effect on PC box-girder," Journal of Southeast University (Natural Science Edition), vol. 38, no. 6, pp. 1105-1109, 2008.

[13] Z. W. Song, J. Z. Xiao, and L. M. Shen, "On temperature gradients in high-performance concrete box girder under solar radiation," Advances in Structural Engineering, vol. 15, no. 3, pp. 399-415, 2002.

[14] D. Yang, T. Yi, H. Li, and Y.-F. Zhang, "Monitoring and analysis of thermal effect on tower displacement in cablestayed bridge," Measurement, vol. 115, pp. 249-257, 2008.

[15] D. Li, M. A. Maes, and W. H. Dilger, "Thermal design criteria for deep prestressed concrete girders based on data from Confederation bridge," Canadian Journal of Civil Engineering, vol. 31, no. 5, pp. 813-825, 2004.

[16] B. D. Hedegaard, C. E. W. French, and C. K. Shield, "Investigation of thermal gradient effects in the I-35W st. Anthony falls bridge," Journal of Bridge Engineering, vol. 18, no. 9, pp. 890-900, 2013.

[17] Y. Wang and J. S. Ye, "Analysis and control of temperature gradient's influence on formwork erection elevation during balanced cantilever cast-in-place segmental construction of concrete girder," Journal of Highway and Transportation Research and Development, vol. 26, no. 8, pp. 89-93, 2009.

[18] X. Song, F. Hani Melhem, J. Li, Q. Y. Xu, and L. J. Cheng, "Effects of solar temperature gradient on long-span concrete box girder during cantilever construction," Journal of Bridge Engineering, vol. 21, no. 3, Article ID 04015061, 2016.

[19] J. S. Zhou and Z. H. Lou, "The status quo and developing trends of large span prestressed concrete bridges with continuous rigid frame structure," China Journal of Highway and Transport, vol. 13, no. 1, pp. 31-37, 2000.
[20] O. Larsson, "Climatic thermal stresses in the Vätösund boxgirder concrete bridge," Structural Engineering International, vol. 22, no. 3, pp. 318-322, 2012.

[21] B. Gu, Z. J. Chen, and X. D. Chen, "Measurement and simulation on solar temperature field of large size concrete box girder," Journal of Central South University (Science and Technology), vol. 44, no. 3, pp. 1252-1261, 2013.

[22] M. M. Elbadry and A. Ghali, "Temperature variations in concrete bridges," Journal of Structural Engineering, vol. 109, no. 10 , pp. 2355-2374, 1983.

[23] F. Bason, "Diffuse solar irradiance and atmospheric turbidity," in Proceedings of the Euro Sun 2004 Conference Proceedings, pp. 1-7, Freiburg, Germany, June 2004.

[24] A. Saetta, R. Scotta, and R. Vitaliani, "Stress analysis of concrete structures subjected to variable thermal loads," Journal of Structural Engineering, vol. 121, no. 3, pp. 446-457, 1995.

[25] M. S. Bohn and R. Anderson, "Temperature and heat flux distribution in a natural convection enclosure flow," Journal of Heat Transfer, vol. 108, no. 2, pp. 471-475, 1986.

[26] O. Larsson and R. Karoumi, "Modelling of climatic thermal actions in hollow concrete box cross-sections," Structural Engineering International, vol. 21, no. 1, pp. 74-79, 2011.

[27] China Communications Highway Planning and Design Institute Co., Ltd., General Specifications for Design of Highway Bridges and Culverts, People's Transportation Press, Beijing, China, 2015.

[28] American Association of State Highway and Transportation Officials, AASHTO LRFD Bridge Design Specifications, American Association of State Highway and Transportation Officials, Washington, DC, USA, 2017.

[29] New Zealand Transport Agency, Bridge Manual (SP/M/022), New Zealand Transport Agency, Wellington, New Zealand, 2013.

[30] European Committee for Standardization, Eurocode 1: Actions on Structures-Part 1-5: General Actions-Thermal Actions, European Committee for Standardization, Brussels, Belgium, 2004. 